\title{
Reliability Evaluation of Lithium-Ion Batteries for E-Mobility Applications from Practical and Technical Perspectives: A Case Study
}

\author{
Foad H. Gandoman 1,2 ${ }^{\mathbb{D}}$, Emad M. Ahmed ${ }^{3, * \mathbb{D}}$, Ziad M. Ali 4,5 ${ }^{\mathbb{D}}$, Maitane Berecibar 1,2, Ahmed F. Zobaa ${ }^{6}$ (D) \\ and Shady H. E. Abdel Aleem $7, *$ (D)
}

1 Logistics and Automotive Technology Research Centre, Research Group MOBI-Mobility, Vrije Universiteit Brussel, 1050 Brussel, Belgium; Foad.Heidari.Gandoman@VUB.be (F.H.G.); maitane.berecibar@vub.be (M.B.)

2 Flanders Make, 3001 Heverlee, Belgium

3 Department of Electrical Engineering, College of Engineering, Jouf University, Sakaka 72388, Saudi Arabia

4 Electrical Engineering Department, College of Engineering, Prince Sattam Bin Abdulaziz University, Wadi Addawaser 11991, Saudi Arabia; dr.ziad.elhalwany@aswu.edu.eg

5 Electrical Engineering Department, Aswan Faculty of Engineering, Aswan University, Aswan 81542, Egypt

6 Electronic and Electrical Engineering Department, Brunel University London, Uxbridge UB8 3PH, UK; azobaa@ieee.org

7 Department of Electrical Engineering, Valley High Institute of Engineering and Technology, Science Valley Academy, Qalyubia 44971, Egypt

* Correspondence: emamahmoud@ju.edu.sa (E.M.A.); engyshady@ieee.org (S.H.E.A.A.)

check for updates

Citation: Gandoman, F.H.; Ahmed, E.M.; Ali, Z.M.; Berecibar, M.; Zobaa, A.F.; Abdel Aleem, S.H.E. Reliability Evaluation of Lithium-Ion Batteries for E-Mobility Applications from Practical and Technical Perspectives: A Case Study. Sustainability 2021, 13, 11688. https://doi.org/10.3390/ su132111688

Academic Editor: Nicu Bizon

Received: 26 September 2021

Accepted: 19 October 2021

Published: 22 October 2021

Publisher's Note: MDPI stays neutral with regard to jurisdictional claims in published maps and institutional affiliations.

Copyright: (c) 2021 by the authors. Licensee MDPI, Basel, Switzerland. This article is an open access article distributed under the terms and conditions of the Creative Commons Attribution (CC BY) license (https:// creativecommons.org/licenses/by/ $4.0 /)$.
Abstract: Evaluation of the reliability of the components of electric vehicles (EVs) has been studied by international research centers, industry, and original equipment manufacturers over the last few years. Li-ion batteries are the main sensitive component of an EV's E-power train. In other words, the Li-ion batteries for electromobility applications are one of the main components of an EV, which should be reliable and safe over the operational lifetime of the EV. Thus, investigating how to assess the reliability of the Li-ion battery has been a highly recommended task in most European projects. Moreover, with the increase in the number of new EVs made by European car companies, there has been a competition for market acquisition by these companies to win over customers and gain more market share. This article presents a comprehensive overview of the evaluation of the reliability of Li-ion batteries from practical and technical perspectives. Moreover, a case study for assessing reliability from practical and technical perspectives has been investigated.

Keywords: capacity fade; electric vehicles; electromobility applications; Li-ion batteries; power fade; reliability

\section{Introduction}

At the beginning of 2020, the main original equipment manufacturers (OEMs) launched their electric vehicles (EVs) on the e-mobility applications markets in all parts of Europe. This event promises to create a competitive market and large investments in the field of the electric transport system in Europe and around the world for these companies. As a result, with the increase in numbers of various products in the sales market, technical and economic challenges will present new dimensions [1,2]. Meanwhile, the concept of reliability evaluation of the Li-ion batteries has become an essential issue in this area, for the performance of future electric vehicles [3,4]. Figure 1 represents the strong connection of reliability with key aspects of Li-ion batteries, and the number of the published articles (1257) (based on Scopus) from 1994 to 2020. Consequently, evaluating the reliability of Li-ion batteries in this area from practical and technical perspectives has been receiving attention. 


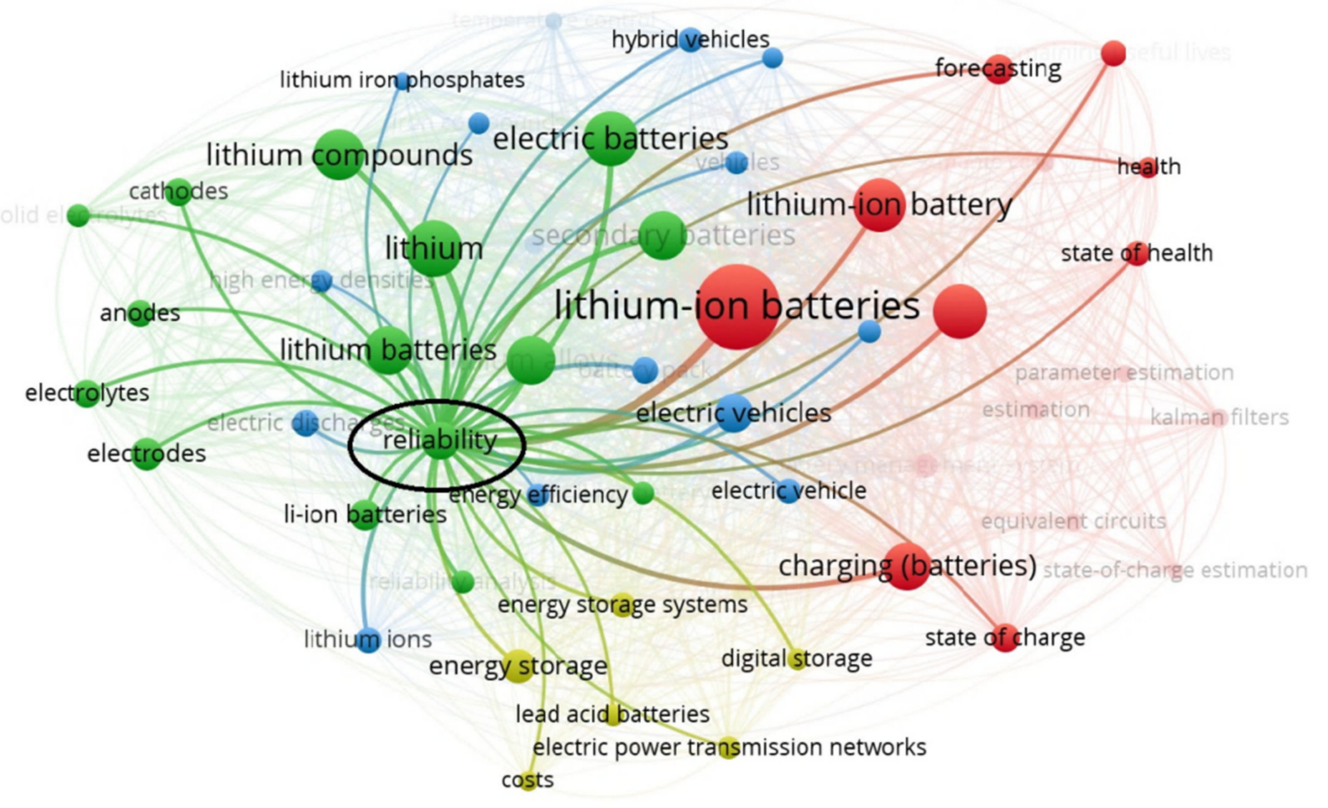

(a)

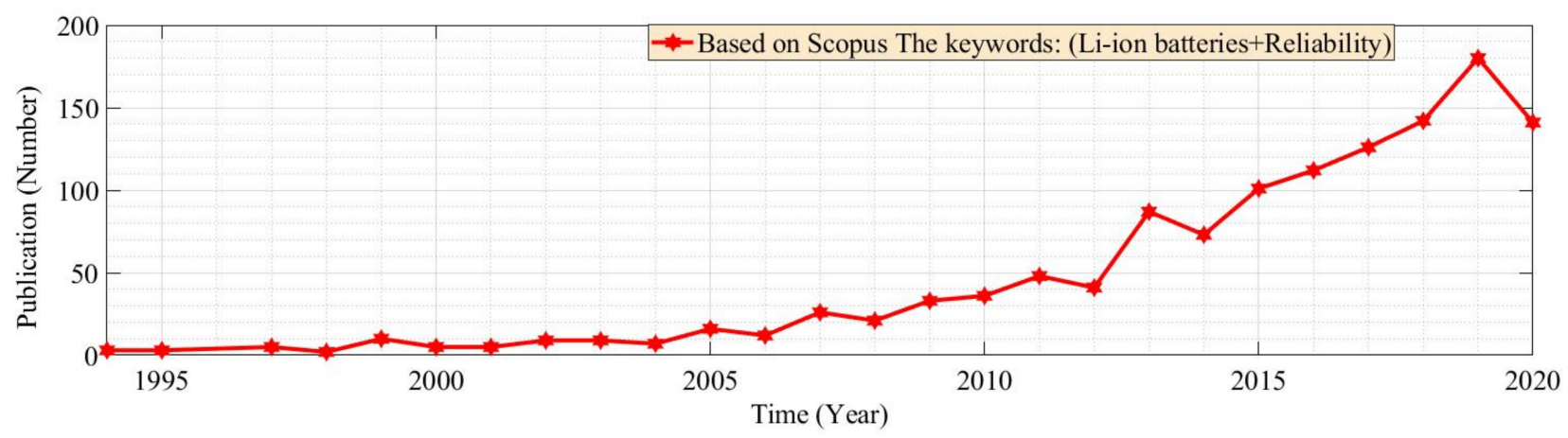

(b)

Figure 1. Concept of reliability evaluation of the Li-ion batteries importance: (a) Connection between the reliability and Li-ion batteries aspects, and (b) Number of the published publications based on the Scopus from 1994 to 2020.

To investigate the mechanisms that lead to degradation, both quantitative analysis (non-invasive diagnostic techniques) and qualitative analysis (post-mortem) methods are used [5-8]. However, assessing reliability means evaluating the probability of the occurrence of faults/degradation and their effect on the available capacity and power of the Li-ion batteries [9]. Thus, quantitative analysis techniques have been used in the reliability evaluation of Li-ion batteries $[10,11]$. Moreover, to evaluate the reliability of the Li-ion batteries, the following main reliability tools have been used: (i) fault tree analysis (FTA) [12], (ii) the failure modes effects analysis (FMEA) [13], and (iii) qualitative analysis techniques $[14,15]$.

In Ref. [16], the role of the degradation mechanisms and their effect on the performance of the Li-ion batteries in the EVs are presented. In Ref. [17], the effect of overcharging has been discussed. The effect of the configuration of the battery pack and the arrangement of the cells on improving the reliability of the Li-ion battery pack has been studied [18]. A comprehensive overview regarding the effect of the aging mechanism on the lifetime of the Li-ion batteries has been taken into consideration [19]. In Ref. [9], a comprehensive review in terms of quantitative analysis methods for the reliability assessment of Li-ion batteries was studied. A quantitative analysis of the reliability based on the investigation of capacity fade (CF) and solid electrolyte interphase (SEI) was studied in Ref. [20]. Quantitative 
analysis using the time-domain for appraising the reliability of Li-ion batteries based on the effect of the electrochemical impedance spectroscopy was investigated in Ref. [10]. In Ref. [21], the FMEA has been investigated as one of the reliability assessment tools in Li-ion batteries. In Ref. [13], multiple failure mechanisms and their effects on battery health and safety have been studied.

The primary gaps in the reliability assessment of Li-ion batteries are:

1. reliability indicators and their connection with degradation modes, degradation mechanisms, and degradation conditions need to be taken into consideration;

2. multi-degradation conditions (different temperatures and C-rates) of the Li-ion batteries need to be investigated as to their effect on the reliability indicators;

3. the reliability of the Li-ion battery in terms of the time and frequency domains need to be considered;

4. degradation conditions and their comparison from the reliability standpoint should be investigated.

To fulfill these objectives, $\mathrm{CF}$ and power fade (PF) have been introduced as two main effects of degradation of Li-ion batteries. CF decreases the amount of energy in a Li-ion cell due to cycling (charge and discharge) and storage. The CF for battery cells happens with a $20 \%$ capacity reduction, which is called the battery's end of life (EoL) [22]. The rate of CF is notably related to temperature, depth of discharge (DoD), charging condition (C-rate), and load profiles (discharge procedure) [23]. PF decreases the amount of power that can be delivered by a Li-ion battery, due to a growth in the internal impedance of the cell [24]. The purpose behind this work is a better understanding of how to evaluate the reliability of a Li-ion battery for providing solutions to existing challenges.

The main objectives of this paper are outlined below:

- Investigating the concept of the reliability of Li-ion batteries;

- A comprehensive investigation of the degradation of Li-ion batteries in normal operation;

- The contribution of $\mathrm{CF}, \mathrm{PF}$, and open-circuit voltage to Li-ion batteries' reliability;

- The role of the reliability indicators in the performance of Li-ion batteries.

The paper is organized as follows: Li-ion battery technologies are explained in Section 2. Degradation in a Li-ion battery, its causes, and outcomes are presented in Section 3. Reliability evaluation for Li-ion batteries is presented in Section 4. Laboratory results are presented in Section 5, and our conclusions are presented in Section 6.

\section{Li-Ion Battery Technologies}

\subsection{The Components of Li-Ion Batteries}

Due to their high power and energy density, long life span, very affordable work temperatures, high voltage, low volatility rates, and other positive properties, lithium-ion batteries are used in a wide range of applications. The gradual improvement in their performance and a significant reduction in the cost of these types of batteries has led to their increasing exploitation in moveable electronic devices, such as mobile phones, tablets, and EVs. However, the high speed of technology growth in the various domains has led to the need for cheaper, more reliable, and better-performing batteries [6]. Figure 2 shows the components of a family of Li-ion batteries and typical Li-ion battery packs. Moreover, Lithium-Sulfur (Li-S), due to its advantages, will be a new family of Li-ion batteries [8,9]. According to Figure 2, there are five main components in the Li-ion batteries: anode, cathode, electrolyte, separator, and current collector.

Different types of rechargeable batteries have also been introduced, and several of them have been given more attention for proper performance in EVs. Different types of technologies are frequently used for battery cells on Carbon (C) Anode material LithiumIron-Phosphate (LFP), Nickel-Manganese-Cobalt (NMC), Nickel-Cobalt-Aluminum-Oxide (NCA), Lithium-ion Manganese Oxide (LMO), and Lithium Titanium Oxide (LTO) from the cathode side [7]. 
Conventional Li-ion battery batteries in the automotive industry
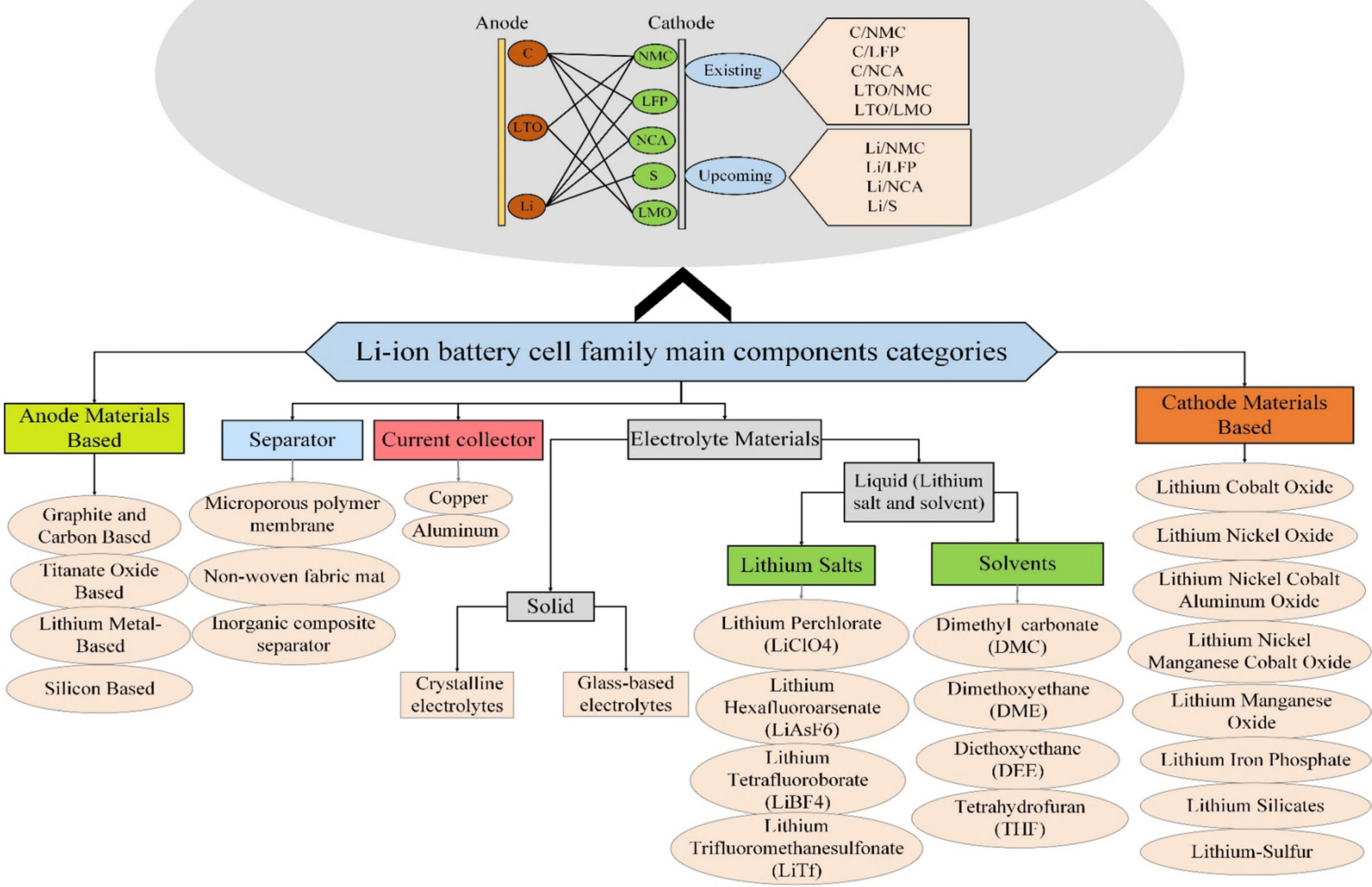

Figure 2. Components of the conventional Li-ion battery cells in the automotive industry.

\subsection{The Physical Implementation of Li-Ion Batteries}

There are three main shapes for the individual cell used in the EV's battery pack [25]: cylindrical, prismatic, and pouch. Table 1 compares the Li-ion batteries from the physical perspective. According to Table 1, the main factors for comparing the different $\mathrm{Li}$-ion batteries from a shape perspective are energy density, heat management, mechanical strength, electrode arrangement, and specific energy. In general, the prismatic cell has become well known because of its better performance.

Table 1. Li-ion battery comparison from the physical implementation perspective.

\begin{tabular}{cccc}
\hline Name & Cylindrical & Prismatic & Pouch \\
\hline Shape & & & \\
& & & \\
& Wound & Wound & \\
Arrangement of electrode & Best & Good & Wound \\
Mechanical stability & Bad & Good & Good \\
Heat management & Good & Good & Best \\
Specific energy & Good & Gest & Good \\
Energy density & & &
\end{tabular}




\subsection{Definitions Regarding Li-Ion Batteries}

\subsubsection{Voltage and Capacity}

The two most important parameters in a Li-ion battery are voltage and capacity. The voltage, expressed in volts, measures the electrochemical potential available in the cell, which is determined by the type of active material contained in the cell. Moreover, the mass of the active material determines the cell capacity. The capacity is a measure (in $\mathrm{Ah}$ ) of the charge which can be stored in the battery and indicates the energy that can be extracted from the battery. The nominal rated capacity is usually defined by the battery manufacturers and determined under specific conditions. However, different operating conditions and battery aging can strongly affect the real capacity of the battery, which reduces the available stored energy [26].

\subsubsection{State of Charge and Depth of Discharge}

The state of charge $(\mathrm{SoC})$ of a battery can be described as the proportion between the charge available at a specific time and the total available charge when the battery is fully charged, and is expressed in percentage and varies between 0 and 100 . In Li-ion barriers, there are three main areas of operations from the SoC perspective: exponential area, nominal area, and discharge area.

If we look at how battery capacity usually performs server timing, we can see three distinct phases. In the first stage, the rate of capacity fade rapidly decays as the solid electrolyte interferes with stabilizers and becomes less reactive to the electrolyte. Although battery degradation is a non-linear process, the second stage (until the knee point) represents the linear region. Once we enter the knee, the degradation mechanisms occur and result in an increasing rate of capacity loss and cell failure occurs very quickly.

\subsubsection{C-Rate}

The unit of electric current is the ampere (A), but an alternative and potentially more intuitive measure of a battery with respect to its current comes from the definition of the $C$-rate [27]. The $C$-rate determines the current required to completely charge and discharge a battery in a determined period. For instance, a battery with a nominal capacity of $70 \mathrm{Ah}$ can be entirely charged in one hour applying a current of $70 \mathrm{~A}(\mathrm{C}$-rate $=1 \mathrm{C})$, in two hours at $35 \mathrm{~A}(C$-rate $=\mathrm{C} / 2)$, or in half an hour at $140 \mathrm{~A}(C$-rate $=2 \mathrm{C})[28]$.

\subsubsection{Internal Resistance}

Li-ion batteries' internal resistance is conditional on many factors; therefore, it cannot be considered as a constant. It is generally used to model the voltage drop of the cell under load conditions and the associated power dissipation. There are many different definitions of battery internal resistance present in the literature. The common property in these definitions is the internal resistance, which acts in opposition to the current flow within the battery. The internal resistance is defined as diffusion polarization resistance, and an activation which is the most significant voltage drop in the battery [29].

\subsubsection{Energy and Power}

The energy of a battery is defined as the capacity multiplied by its voltage. The nominal energy depends on the intrinsic electrochemical characteristics of the cell. It is essential to understand that the energy storage capabilities of a battery can vary significantly from their nominal values due to various factors, such as aging, temperature, and operating conditions [30].

The energy, power, cost, safety, and lifetime are the most important parameters to define the performance of a battery. One standard method to compare the performance of batteries, and more generally energy storage devices, is the Ragone plot [31]. Christen and Carlen characterized different Ragone curves for different types of energy storage devices (ESD), highlighting the difference between inductive ESDs (SMEs or flywheels), where energy increases with power, and capacitive ESDs (capacitors and batteries), where 
energy decreases with power [32,33]. While batteries are the ESD with the highest available energy density (especially Li-ion batteries), they are not yet able to completely fulfill the US Advanced Battery Consortium (USABC) requirements for EV applications [31,34].

\section{Degradation in a Li-Ion Battery; Its Causes and Outcomes}

In general, six main degradation conditions affect the reliability of Li-ion batteries [35]:

1. High temperature;

2. Low temperature;

3. High discharge current;

4. High charge current;

5. Over-charge (high SoC);

6. Over-discharge (Low SoC).

A summary of degradations in the Li-ion battery is shown in Figure 3.

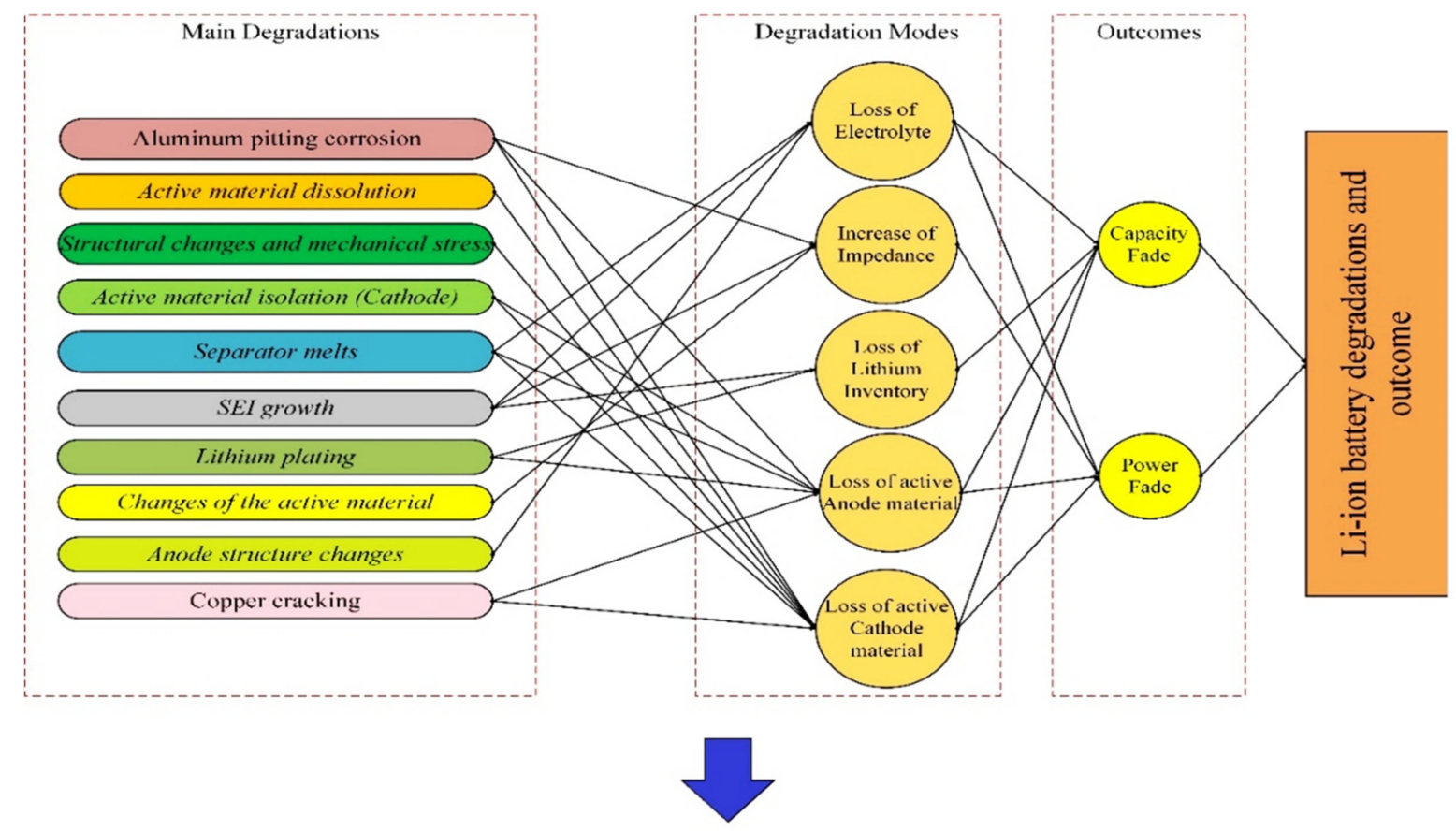

Prioritize of the degradation modes in Li-ion cells (\%)

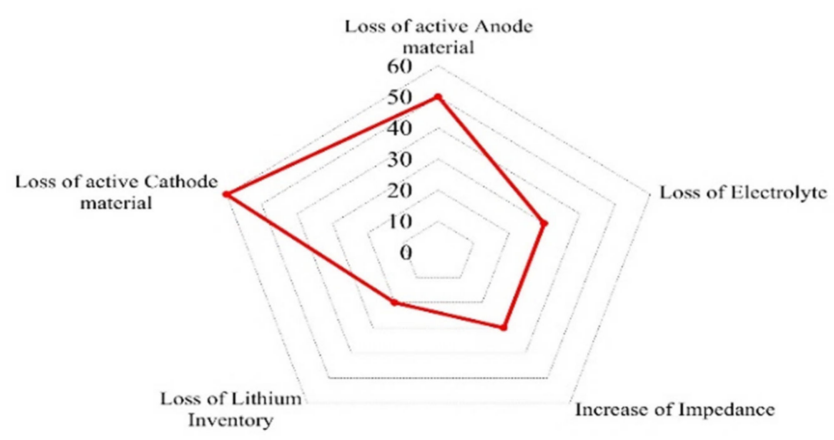

Figure 3. Degradation of the Li-ion batteries.

According to Figure 3, there are many items and conditions which affect the degradation of Li-ion batteries during their operation. In general, the degradation can be split into two main aspects: regular operation aspects and irregular operation aspects. In this work, the regular operation aspects have been discussed. Regarding the regular operation 
aspects, stress factors (Cycling and Calendar) are, again, the main mechanisms that affect the degradation of Li-ion batteries. The red line in Figure 3 shows the rate of the prioritizes of the degradation mode on the reliability of the Li-ion batteries (\%). Among the aging mechanisms, loss of lithium inventory (LLI), loss of active material (LAM), and increases in the cell's internal resistance are mechanisms that play an important role in the aging of Li-ion batteries.

In the cycling aging condition, the most important issues which affect creating the degradations are:

- $\quad$ Low/high temperature [5,36]: At low temperatures, the diffusion rate of lithium ions into graphite during the charging process becomes slow, and Li metal deposition on the surface of the negative electrode can take place with the risk of dendrite formation. This mechanism increases internal resistance and lithium plating (which can ultimately result in a short circuit between the electrodes). High temperatures accelerate the growth rate of the SEI layer on the anode, resulting in accelerated rates of LLI and an increase in the overall cell resistance.

- Over-charge/discharge [37,38]: During overcharging, active lithium is not available on the cathode side and there is no more room for lithium from the anode side. This increases the chance of lithium plating creation and internal heat generation (overheating). Over-discharging increases the internal heat generation, and the anode potential enhances unusually which can lead to the anodic dissolution of the current collector from the anode side.

- High C-rate charge and discharge [39,40]: High charge and discharge currents lead to the same degradation reactions as over-discharge and over-charge. Moreover, high currents also increase the internal temperature and result in metallic lithium plating of the anode due to its limited ability to accept Li-ions at high rates.

The sensitive and reliable modes of the Li-ion batteries are cathode active metric and loss of lithium inventory. Moreover, the most important chemical degradation modes ranged from high to low importance are loss of lithium inventory, an increase of impedance and loss of electrolyte, loss of active anode material, and loss of active cathode material. Thus, to study the concept of reliability in Li-ion cells, these prioritized degradation modes need to be considered. Moreover, the most chief reasons for a decrease in the reliability of Li-ion batteries are aluminum pitting corrosion, separator melts, and SEI growth. This leads, through the effects of capacity and PF, to the Li-ion batteries being in a so-called failure condition.

The environmental temperature of the Li-ion cell can affect its performance. The temperature of the Li-ion battery must be kept in a safe zone $\left(20 \sim 35^{\circ} \mathrm{C}\right)$ due to the direct effect on the performance, health, and safety of the cell. Both very high/low temperatures can shorten the battery life. It is recommended by many researchers that the ideal operating temperature for a battery is in the range of $15-35^{\circ} \mathrm{C}$. At high charging $C$-rate, the internal heat generated by the battery produces LLI and the formation of SEI. This is one of the factors that increases the internal resistance and causes the CF of the battery. Overcharging of the battery causes unwanted heat generation inside the cells. This results in SEI cracking as well as the loss of active region inside the Li-ion cells, which are other factors that play an important role in the CF of the battery. Over-discharge, in contrast, reduces the number of ions contributing to the electrochemical reaction and it is one of the factors of CF in the Li-ion batteries [41].

\section{Reliability Appraisement for the Li-Ion Batteries}

Reliability assessment of a Li-ion battery cell has a strong connection with the electrochemical, thermal, and mechanical properties of the individual cell. However, in the reliability evaluation of the battery pack, not only the reliability of individual cells but also the reliability of other components in the battery pack, such as the thermal management system (cooling system) and battery housing, needs to be considered. Figure 4 shows the difference in the concept of reliability between battery cells and packs. 


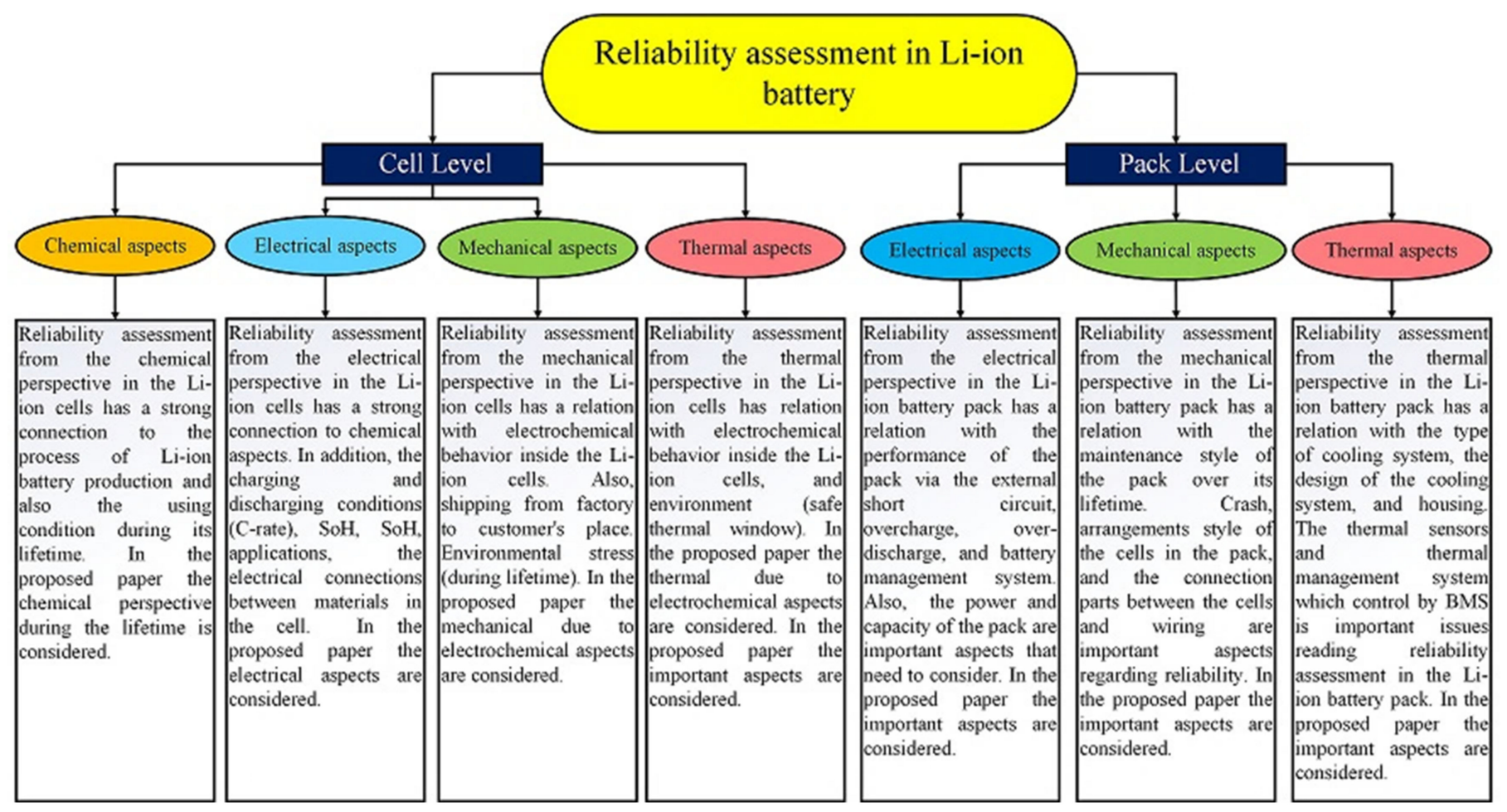

Figure 4. Reliability evaluation aspects for battery cells and packs.

\subsection{Definitions Regarding Li-Ion Batteries}

4.1.1. Fault Tree Analysis (FTA)

FTA describes the connection between degradation, degradation mechanisms, degradation modes, and the effects of the degradation on the output of Li-ion batteries. The mentioned issues for FTA analysis in the Li-ion cells are given as categories in Figure 5. According to Figure 5, the main degradation mechanisms are thermal, electrical, mechanical, and chemical issues in the Li-ion batteries [16]. In this work, thermal, electrical, and chemical degradation mechanisms are taken into consideration. Moreover, the logical connection between the basic event (degradation mechanisms) and the basic result (PF and CF) according to FTA analysis is described in Figure 5. Moreover, binder decomposition, separator melting, lithium plating, active material isolation (anode side), SEI growth, and loss of cathode material can be seen as the main degradations [35]. The degradation modes are conductivity loss, loss of active cathode material, loss of active anode material, and LLI [42,43]. Finally, PF and CF are essential factors in the effects of the degradation modes on the efficiency of the Li-ion batteries in the FTA analysis.

\subsubsection{Failure Mode and Effects Analysis (FMEA)}

The method of FMEA was applied in the context of Li-ion batteries to analyze the degradation of an electrochemical process. According to the aging mechanisms, degradation mode, and degradation conditions, a battery can also be considered a complex multi-domain system and could affect other subsystems in e-mobility and stationary applications. Figure 6 shows the FMEA results concerning battery components. The results show why the component fails and how it affects the whole battery. 


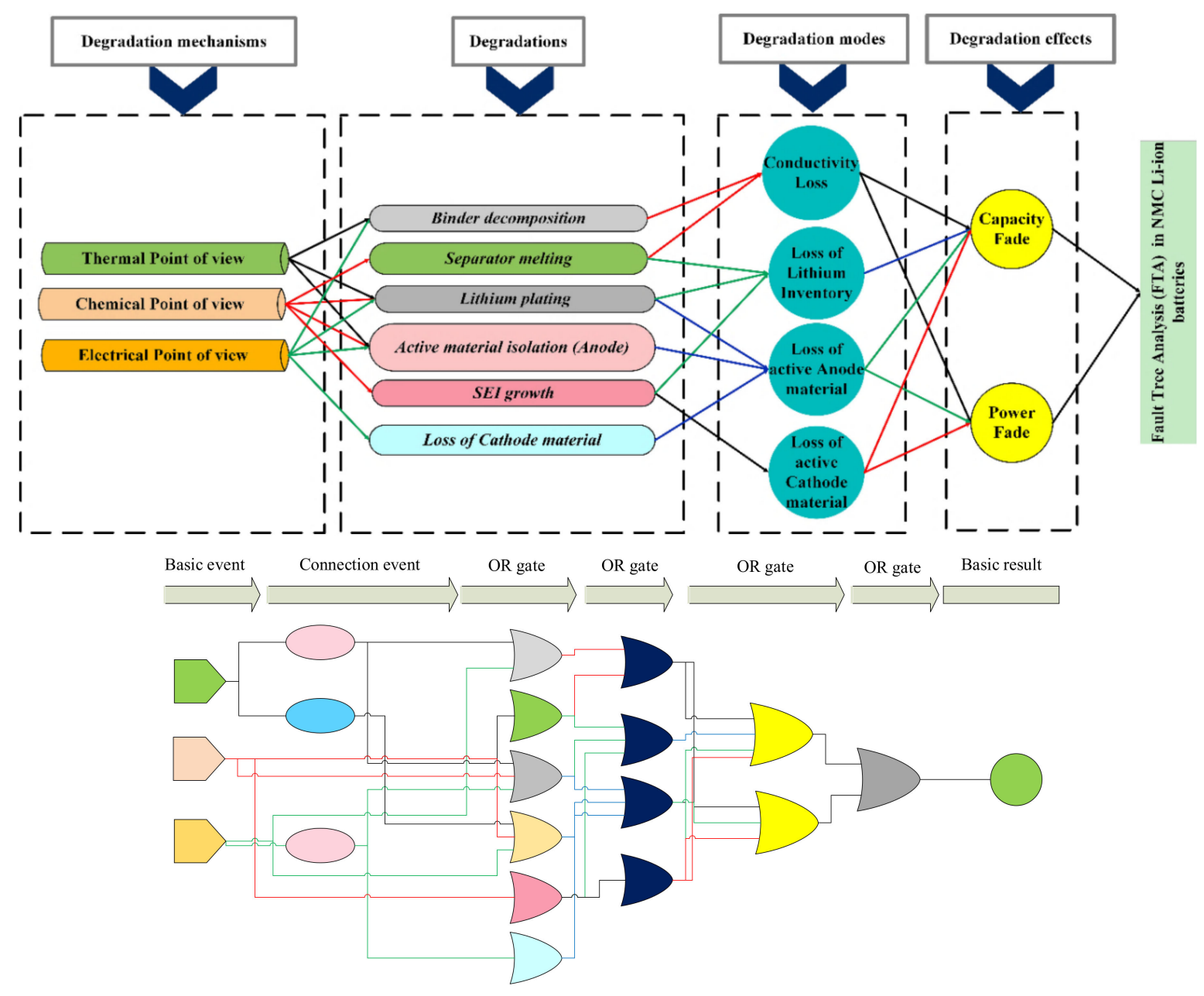

Figure 5. FTA in the Li-ion batteries.

\subsubsection{Quantitative Analysis: Time-Domain}

Pre-conditioning: The pre-conditioning test consists of several discharge and charge cycles of the battery to prepare the cell (initiating Lithium/electron flow) for future testing procedures. Through this test, the first initial capacity value of the battery is calculated. The analysis is performed at controlled ambient temperature $\left(25^{\circ} \mathrm{C}\right)$ and starts with a status check of the cell, continuing with a standard charge at Constant Current (CC) followed by Constant Voltage (CV) phases and the discharge with the CC. It continues by charging and discharging three times in a row. The $C$-rates are a compromise value between time and degradation. Each time a discharge or charge is finished, a $3 \mathrm{~h}$ pause is implemented.

Capacity test: The available capacity after every three cycles (in this research, the number of the multi-cycle is 50 times) the discharge capacity test has been measured. In other words, after every 50 cycles, the batteries are charged and discharged in 3 or 5 cycles according to the previous capacity level. The value of the discharge capacity $(100 \% \mathrm{SoC})$ picks up the available capacity of the batteries and is used as the available $C$-rate in the second aging test.

OCV versus SoC test procedure: The open-circuit voltage (OCV) test considers determining the relationship between the SoC and the OCV of the cell. The test profile includes a complete charge followed by full discharge of the cell in steps of $5 \%$ between $100 \%$ and $0 \% \mathrm{SoC}$ window of the available discharge capacity of the battery at $\mathrm{C} / 2$. The capacity related to this $C$-rate will be already available from the calculation during the "discharge capacity test" at the $\mathrm{C} / 2$ discharge pulse for each temperature. After each step, a relaxation period of $3 \mathrm{~h}$ has been implemented. Complete discharge and a series of charge pulses 
are applied to have the discharging and charging OCV behaviors. The voltages during each rest term are measured to indicate the OCV behavior of the Li-ion batteries. Therefore, $\mathrm{OCV}$ against SOC values can be forecasted or found from the measured data points by interpolation or fitting techniques, respectively.

HPPC test procedure: The hybrid pulse power characterization (HPPC) test measures the impedance of the Li-ion batteries using a test profile that contains both discharge and charge pulses. The main target of the test is to determine the DC internal resistance of the three tested cells (time-domain). The internal resistance is responsible for the irreversible heat generation, and a measurable degradation is expected that increases its value at every $\mathrm{SoC}$ and $\mathrm{C}$-rate. Thus, as a function of the $\mathrm{SoC}$, the current rate, and the temperature, the internal DC resistance is determined for an extensive range of SoC points, currents, and temperatures. The idea of this test is to apply a $10 \mathrm{~s}$ discharge pulse and $10 \mathrm{~s}$ charge-pulse power capabilities at each given $\mathrm{SoC}$ and for different $C$-rates. A $600 \mathrm{~s}$ rest period is scheduled between each HPPC pulse. Figure 7 shows an example of a standard HPPC pulse train.

\section{FMEA analysis in the Li-ion batteries}

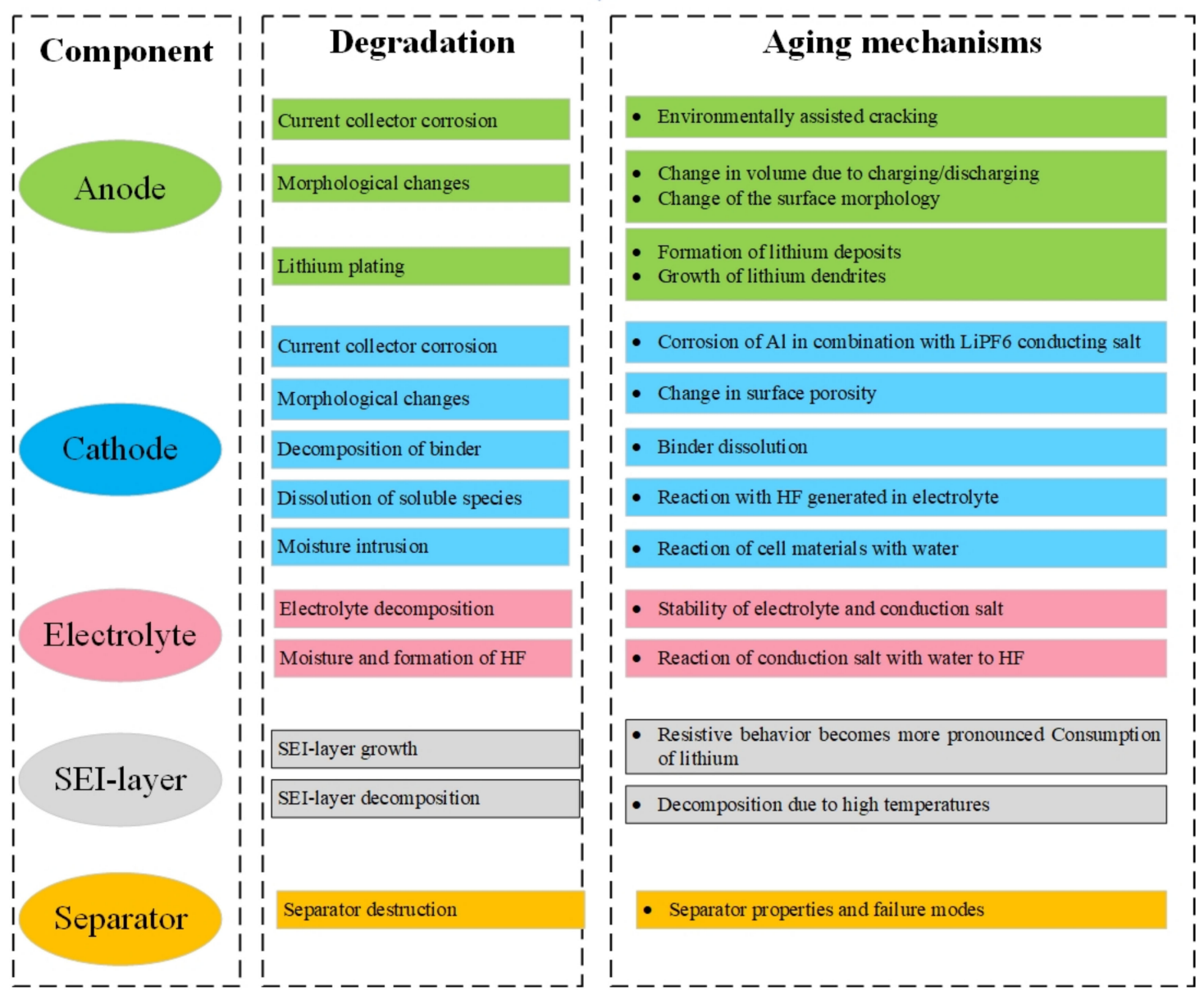

Figure 6. FMEA results concerning battery components adopted from [44]. 


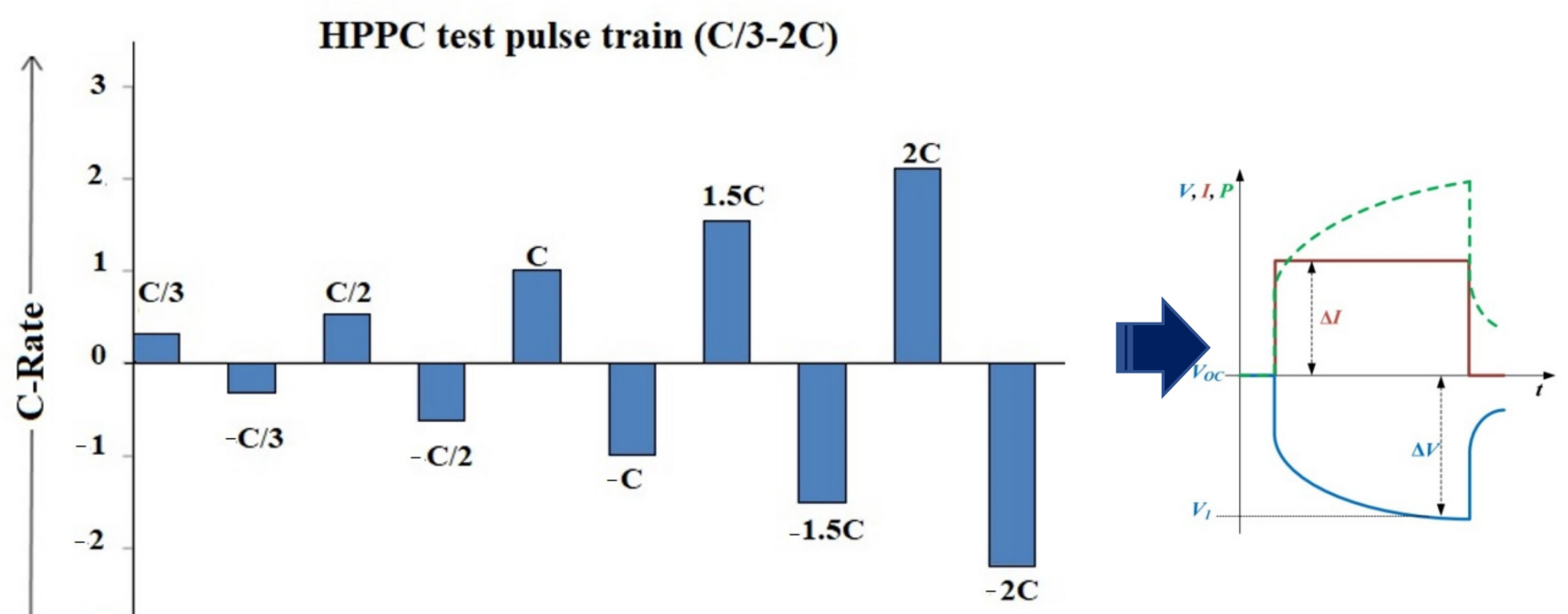

Time (S)

Figure 7. Example of an HPPC pulse train adopted from [45].

The rates of the internal resistance based on the $C$-rate domains are calculated as follows:

$$
R=\frac{\Delta V}{\Delta I}=\frac{V-V_{O C}}{I}
$$

By Equations (2) and (3), the discharge pulse power density and regenerative pules power density can be calculated, respectively.

$$
\begin{aligned}
& \text { Discharge pulse power desnsity }=\frac{V_{t 1} \times I_{\text {discharge }}}{\text { Weight }} \\
& \text { Regenerative pulse power desnsity }=\frac{V_{t 3} \times I_{\text {regen }}}{\text { Weight }}
\end{aligned}
$$

Here, $V_{t 1}$ is the voltage at the end of discharge, and $V_{t 3}$ stands for the voltage of the regenerative pulse. Moreover, $I_{\text {discharge }}$ is the current pulse during discharge, and $I_{\text {regen }}$ stands for current pulses during charge. Finally, $R_{\text {discharge }}$ and $R_{\text {regen }}$ are the values of resistance at each particular frequency domain.

Li-ion battery internal impedance is demonstrated by an electrical circuit composed of passive elements connected in series. The proposed internal impedance explains impedance behavior at various frequencies [46]. Figure 8 shows the passive components in the Li-ion batteries. The Warburg impedance $(\mathrm{ZW})$ describes the impedance at a given frequency, and it is usually simplified as a resistance and a capacitance in parallel. This impedance demonstrates the phenomena of lithium diffusion in the porous active material from the side of the electrode. ZARC1 impedance is described by the second arc of a circle in Figure 8, in which Figure 8 shows the capacitive effect of the double-layer interface and the resistance to the transfer of charges to the electrodes. ZARC2 impedance is described by the first arc of a circle in Figure 8. It is not always detected and represents the ohmic-capacitive effects of the SEI formed during charge and discharge cycles on the anode surface.

The internal resistance $\left(R_{1}\right)$ is shown in the intersection point between the $x$-axis, the real part of $Z$, and the impedance Nyquist diagram (zero-intercept Nyquist diagram point). It indicates the sum of the resistances of electrodes, electrolytes, SEI, and current collectors. Besides, L denotes the inductive reactance because of the metal elements of the cables and battery at a very high frequency. 


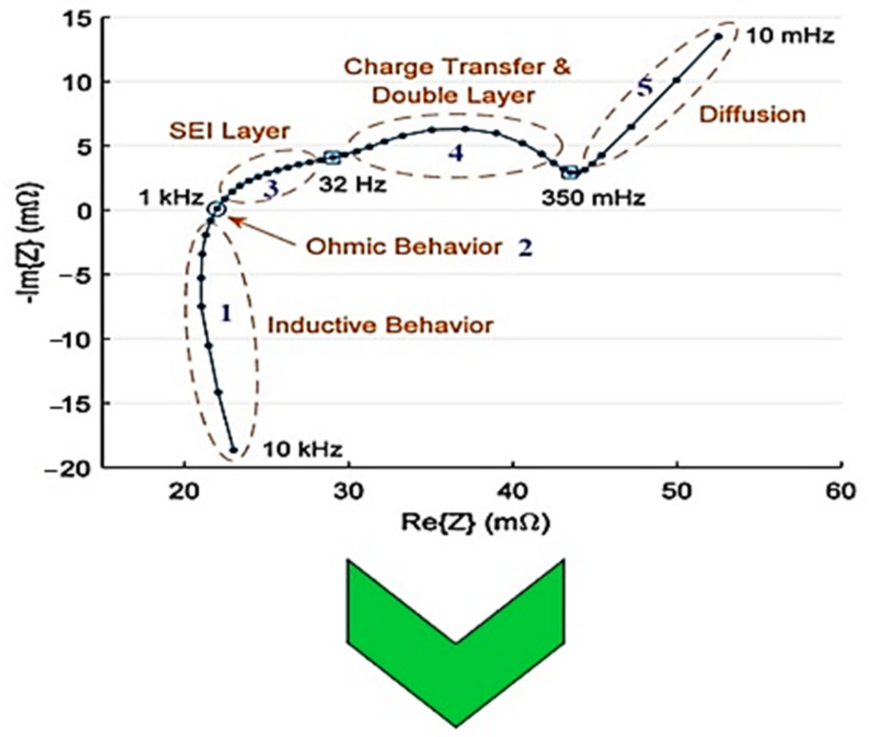

Copper foil Anode
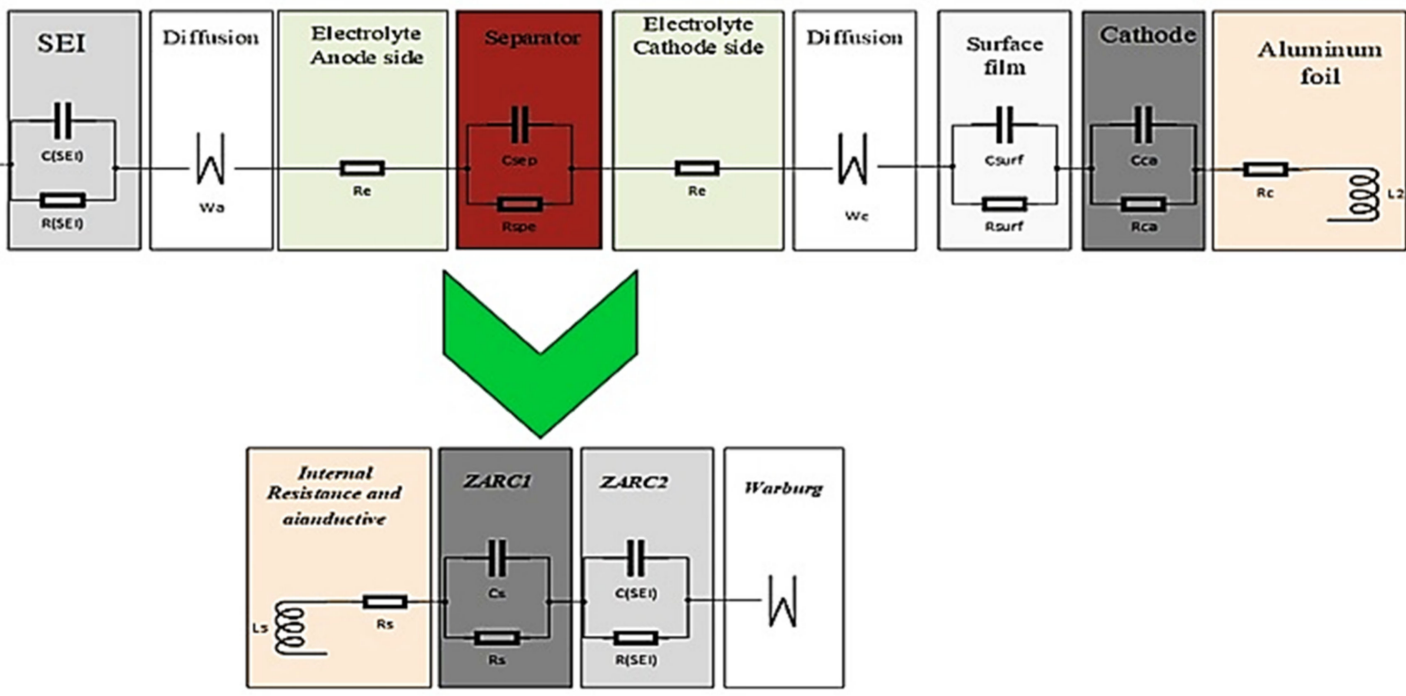

Figure 8. Impedance spectrum of a Li-ion cell with details of all elements.

\subsection{Reliability Indicators}

4.2.1. Capacity Fade

Different definitions for battery capacity are given in the literature [47]. Figure 9 shows the four main ones -nominal capacity, initial capacity, actual capacity, and CF.

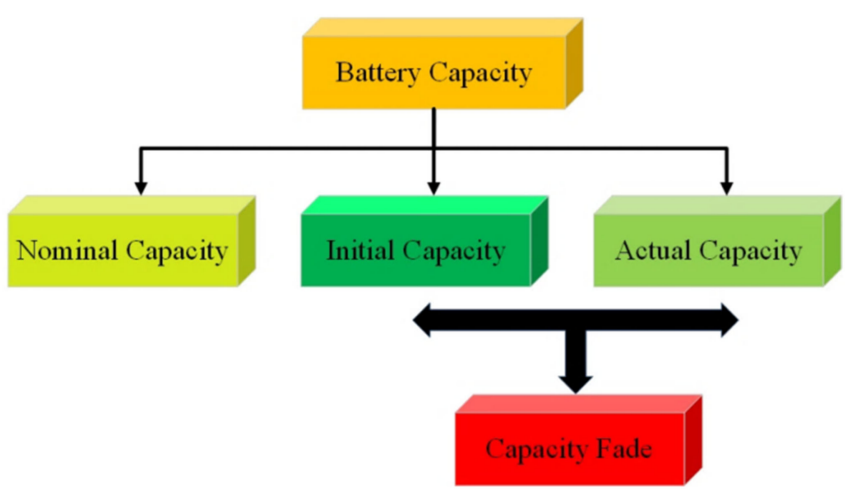

Figure 9. Battery CF definition. 
The nominal capacity is the battery's capacity determined by the manufacturer for operation under nominal conditions $\left(25^{\circ} \mathrm{C}\right.$ and standard charge and discharges currents). The initial capacity describes the highest rate of charge that can be extracted from the battery in initial cycles. The actual capacity is the highest rate of charge that can be measured from the battery in its initial cycles. The difference between the initial and the actual capacities is the capacity loss caused by aging effects. The $\mathrm{CF}$ and $\mathrm{SoH}$ variation of the battery at $25^{\circ} \mathrm{C}$ under standard test protocols (the manufacturer's datasheet) is shown in Figure 10.

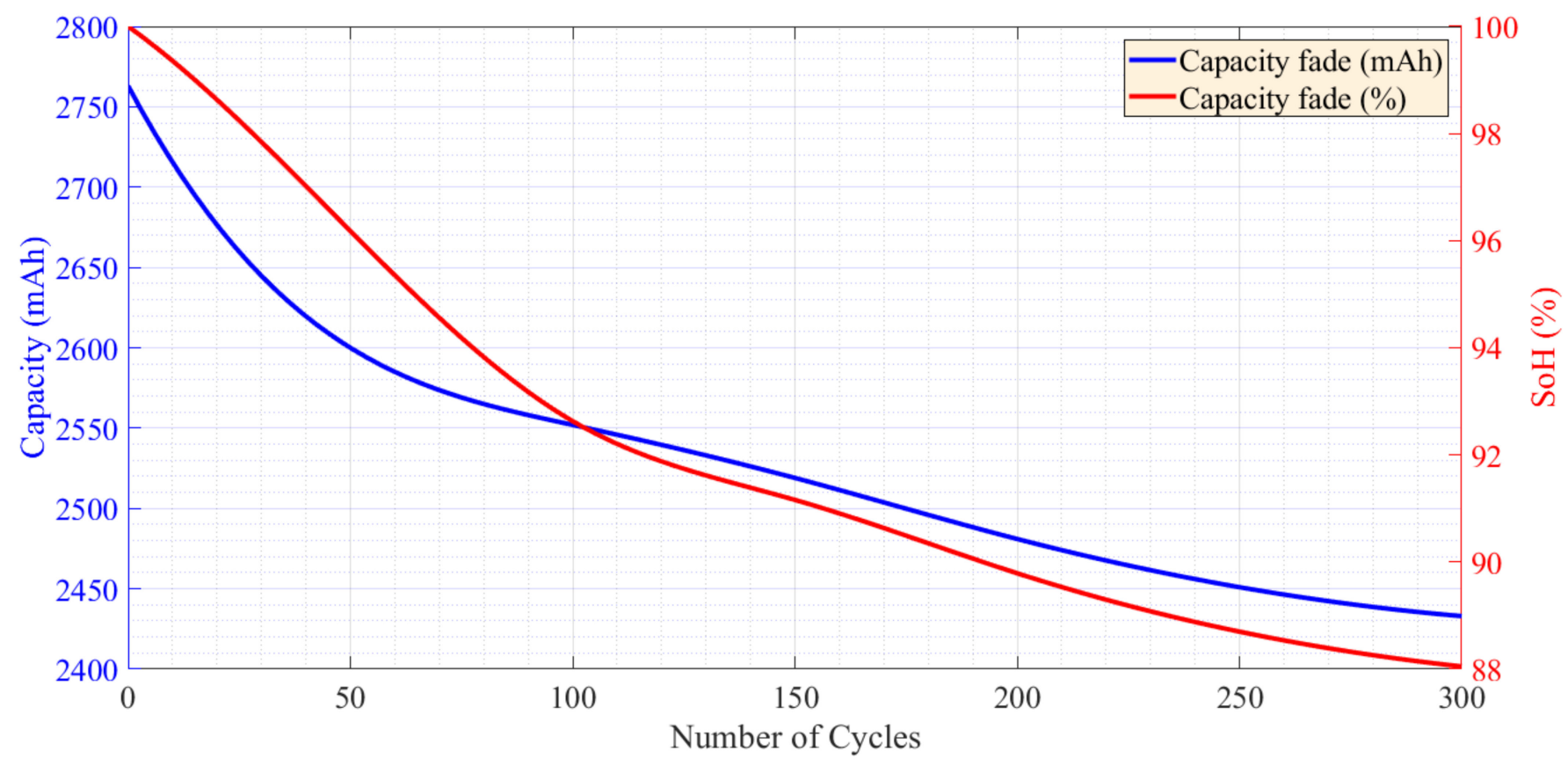

Figure 10. $\mathrm{CF}$ and $\mathrm{SoH}$ variation of the battery at $25^{\circ} \mathrm{C}$ and charge-discharge standard test protocols.

According to Figure 10, the capacity and $\mathrm{SoH}$ at $25{ }^{\circ} \mathrm{C}$ and charge-discharge standard test protocols after 300 cycles are $2433 \mathrm{mAh}$ and $88 \%$, respectively. In the proposed real performance of the NMC cylindrical $3000 \mathrm{mAh}$ Li-ion battery, the nominal capacity, initial capacity, and actual capacity are $3000 \mathrm{mAh}, 2758 \mathrm{mAh}$, and $2440 \mathrm{mAh}$ (after 300 cycles), respectively.

\subsubsection{Power Fade}

PF refers to an increase in the total internal resistance of the battery during its lifetime. Figure 11 shows the total internal resistance $\left(R_{t}\right)$ at different temperatures and under charge-discharge standard test protocols at three points ( $80 \% \mathrm{SoC}, 50 \% \mathrm{SoC}$, and $20 \% \mathrm{SoC})$ during the battery's lifetime.

According to the results, battery internal resistance reduction at $25^{\circ} \mathrm{C}$, the trend has been increased by $20 \% \mathrm{SoC}, 50 \% \mathrm{SoC}$, and $80 \%$, respectively.

In addition, Figure 12 shows the $\mathrm{OCV}$ at $25^{\circ} \mathrm{C}$ under charge-discharge standard test protocols at $80 \% \mathrm{SoC}, 50 \% \mathrm{SoC}$, and $20 \% \mathrm{SoC}$ during the lifetime of the battery. 


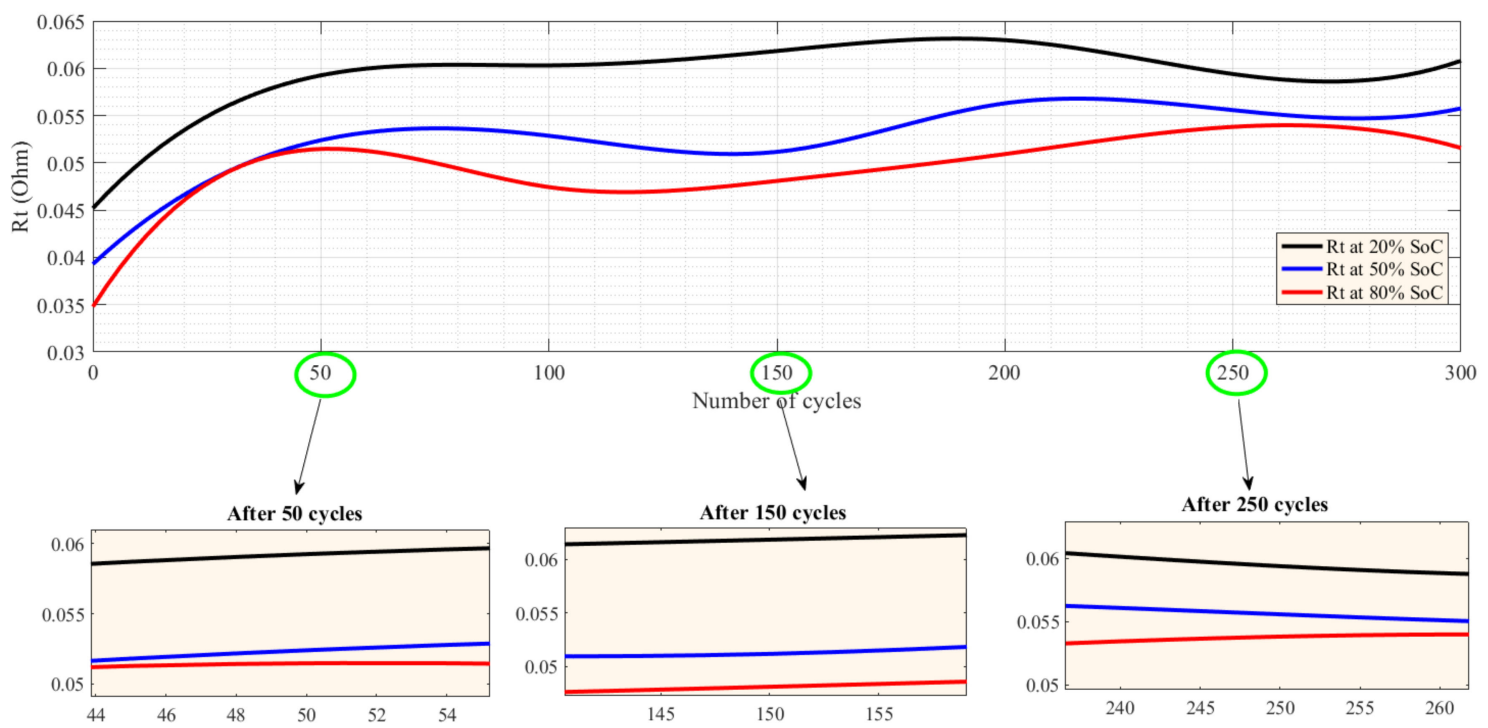

Figure 11. $R_{t}$ behavior at $25^{\circ} \mathrm{C}$ under charge-discharge standard test protocols during the lifetime of the battery after 300 cycles at $25^{\circ} \mathrm{C}$.

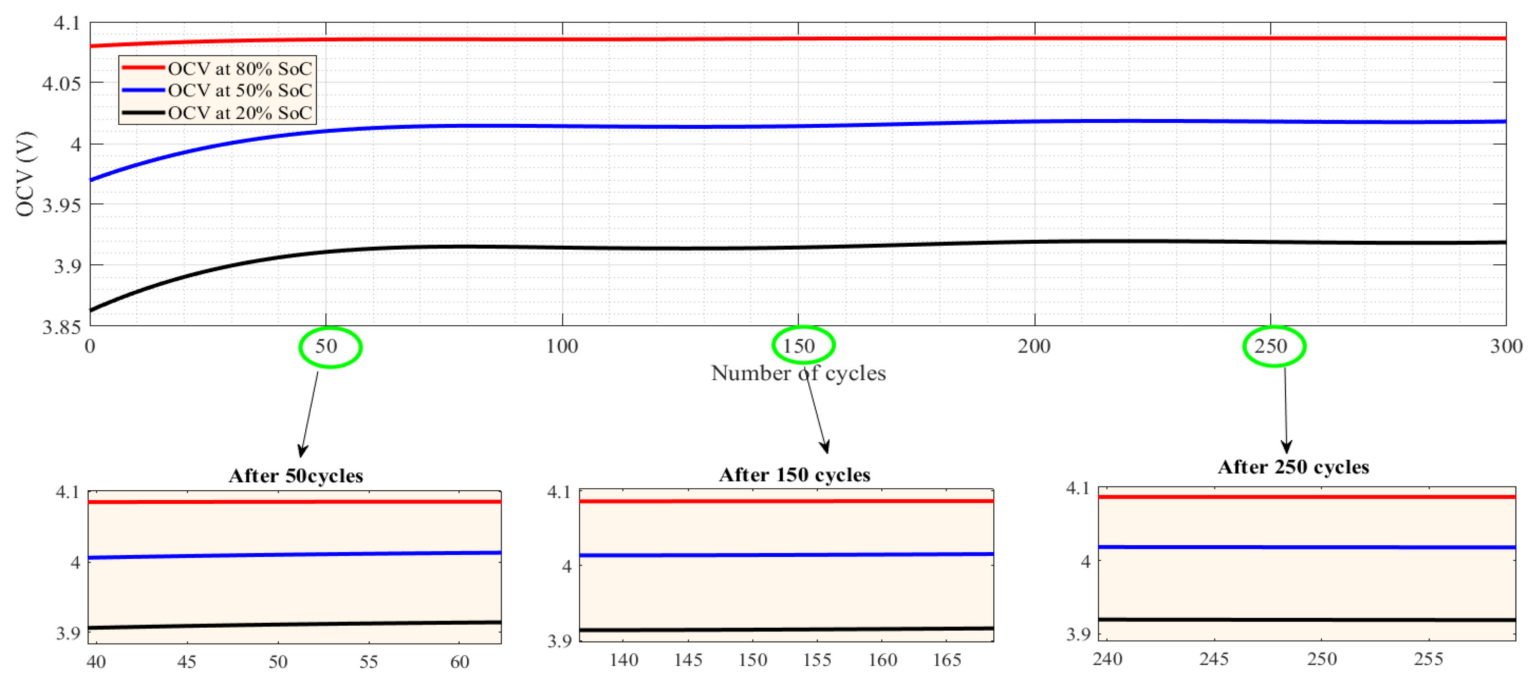

Figure 12. OCV behavior at $25^{\circ} \mathrm{C}$ under charge-discharge standard test protocols during the lifetime of the battery after 300 cycles.

\subsection{Control Strategies for Li-Ion Batteries to Improve Their Reliability}

To ensure safety and reliability and enhance the battery cells' overall performance, a battery management system (BMS) is employed in every application, especially when many cells are interconnected. Battery cell performance is optimal within a safe operation window defined based on the chemistry of the cell, the current rates that are injected, the ambient temperature during operation or calendaring, and the state of health of each battery. Testing procedures that characterize each cell at various conditions are performed, and it has been shown that the reliability of the NMC/C cylindrical cells can be enhanced if certain harmful conditions that trigger degradation mechanisms are avoided [16]. The BMS plays an essential role in this direction, as it estimates the states of the cells and activates all the necessary means to ensure that each cell of the battery stays within the predefined safe operation window. Hence, the reliability of the battery pack is highly dependent on the operation strategy and the functionality of the BMS. Figure 13 shows all the software and hardware aspects for the BMS performance in a battery pack application. These 
features are responsible for monitoring operations, protection against hazards, diagnostics, communication, and management [2]. Nevertheless, all the functionalities from a reliability perspective can be ultimately divided into two main categories: data acquisition and decision-making. In the former, all the functions that have to do with the safety and the protection of the cells individually and as a unit are regarded. In the latter, the BMS is responsible for performing several actions according to the diagnostics so that all the cells are ensured to be within the safe operating area and to achieve an optimal and most efficient operation.

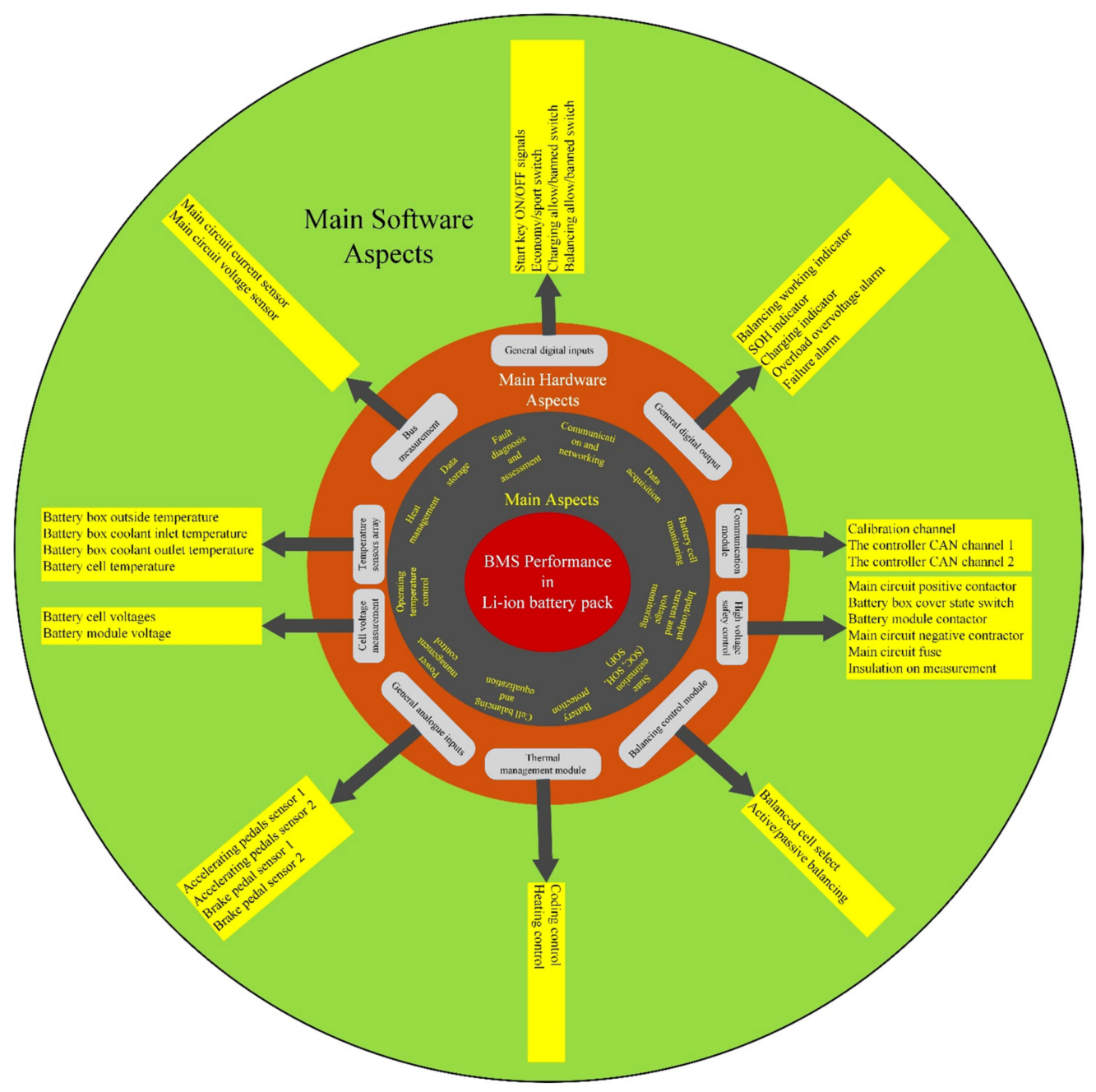

Figure 13. Features of the BMS.

\subsubsection{Data Acquisition and Fault Detection}

To manage the battery pack, BMS requires monitoring of several characteristic parameters of the cells, such as voltage, current, and temperature. Accurate states of the battery cells have to be obtained to avoid extra degradation on the cells, ineffective operation, or worst-case scenarios of thermal runaways. Voltage measurements are one of the most variable parameters to prevent electrical faults, such as over-charge, under-discharge, and isolation faults. BMSs typically use analog-to-digital converters as voltage sensors, which reduces costs and increases reliability. Current sensors are crucial for overcurrent and short circuit protections, whereas thermal sensors manage the heating and cooling requirements.

The number of these needed depends on the thermal distribution of the cells. However, in a multi-cell application, the number of sensors is proportionally increased, which can affect the reliability and the complexity of the system. 
Furthermore, the battery characteristics in real-time measurements are based on these sensors, which can affect the state estimation and decision-making performance of the BMS. To ensure fault detection; hardware redundancy is applied, where the same signal is taken from multiple inputs. In this regard, Xia et al. [4] proposed a fault-tolerant voltage measurement method that reduced the total number of voltage sensors used for in-series orientations without any extra hardware or software. Other approaches suggest that the fault diagnostics on the battery sensors should be based on state estimation techniques such as adaptive or extended Kalman filters (EKF), or observer and fault detection filters. In Ref. [6], Liu et al. used an adaptive EKF to evaluate the residuals of the voltage and current measurements with a cumulative sum algorithm and perform fault diagnostics on the sensors of a battery pack. In Ref. [3], Zheng et al. proposed and validated a rapid and accurate fault diagnosis of the voltage and current sensors with a hybrid system modeling and unscented particle filter approach. In Ref. [7], Yang et al. used a fractional-order modeling approach to investigate the short circuit fault diagnostics based on electrolyte leakage behavior that took place during the fault scenarios. In all cases, the characteristic data of the battery cells in terms of voltage, current, and temperature are obtained in the most accurate way to enhance the system's performance, safety, and reliability.

Fault detection processes have experienced significant developments in the traceability and the location of the faults via machine learning and artificial intelligence to have a more accurate and rapid operation that will further enhance the reliability of the system for fast charging and lifetime management challenges of the battery cells [12]. Figure 14 shows the classification of cell equalization techniques.

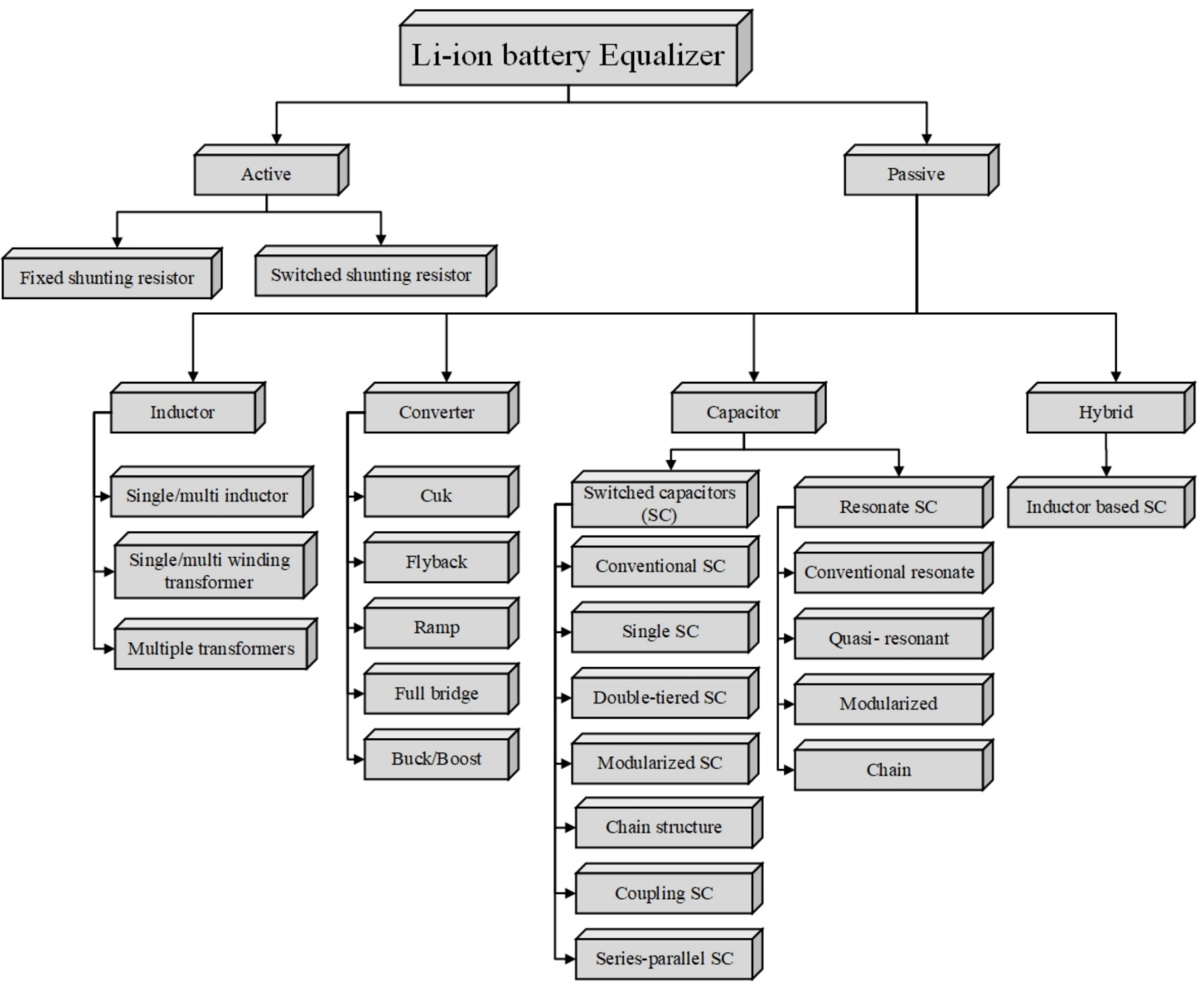

Figure 14. Classification of cell equalization techniques adopted from [48]. 


\subsubsection{Control Strategies and State Estimation}

The data obtained are analyzed with embedded algorithms on the BMS microcontrollers. Typically, a slave BMS is responsible for the data acquisition of a module, while a combination of several modules and BMS-slaves is controlled by a more sophisticated BMS-master unit, the decision taker. The BMS-master is not only responsible for the act and prevent fault scenarios, but for improving the efficiencies of the batteries. It is crucial to accurately estimate the states of the cells under any condition, which can be challenging as the total number of interconnected cells can be large. The states of the cells are categorized into $\mathrm{SoC}, \mathrm{SoH}$ in terms of capacity and power, state-of-balance, i.e., cell equalization [9]. Estimation and management are dependent upon the computational power and the storage capacity of the BMS. Nowadays, with the Internet of Things (IoT) and cloud computing [10], the capabilities of the BMSs can be significantly increased. In real-time, all the relevant information for state estimation and analysis are imported to the cloud, where a digital twin of the battery system is constructed in computers that are many times more powerful than the application's built-in solution.

More complex and robust algorithms like adaptive $\mathrm{H}$-infinity filters and particle swarm optimization can be performed to monitor the cells' capacity and PF of the cells with increased efficiency, accuracy, and reliability [8]. Furthermore, the battery system's reliability is enhanced with the wireless communication established by (IoT), while the creation of big-data libraries of machine learning algorithms can be applied and contribute to the battery aging prognosis and diagnosis [11].

\section{Case Study and Experimental Results}

This section is organized into three main parts. In the first part, the results of the tests at different temperatures $\left(25^{\circ} \mathrm{C}, 45^{\circ} \mathrm{C}\right.$, and $10^{\circ} \mathrm{C}$ degrees) and under charge-discharge standard test protocols $(\mathrm{C} / 2$ charge- $\mathrm{C} / 5$ discharge according to the factory cell's datasheet) are presented. In the second part, the results of the tests under different $C$-rates $(C / 2,1 C$, $2 \mathrm{C}, 3 \mathrm{C}$, and $4 \mathrm{C}$ ) at $25^{\circ} \mathrm{C}$ are presented. The results at high and low discharge currents $\left(\mathrm{C} / 2\right.$ and $\left.4{ }^{\circ} \mathrm{C}\right)$ at different temperatures $\left(25^{\circ} \mathrm{C}, 45^{\circ} \mathrm{C}\right.$, and $10^{\circ} \mathrm{C}$ degrees $)$ are shown in the Section 3. The cycling of batteries continues until the rate of SoH in one of the cells in each classification becomes less than or equal to $80 \%$. Afterward, the results have been compared at that point, according to their classification.

\subsection{CF and SoH at Different Temperatures and under Charge-Discharge Standard Test Protocols}

The NMC cylindrical cell is selected for reliability assessment in the Li-ion batteries in this paper. The batteries underwent the pre-conditioning test at $25^{\circ} \mathrm{C}$ in $\mathrm{BOL}$, and $\mathrm{EOL}$ to investigate the performance of the batteries. Figure 15 a shows the cells in the $25^{\circ} \mathrm{C}$ climate chambers. Moreover, the $\mathrm{CF}$ of the batteries was studied under degradation conditions. The batteries have been considered under cycling tests based on the proposed workflow (Figure 15b). Figure 15c shows the batteries under the test protocols in the climate chambers.

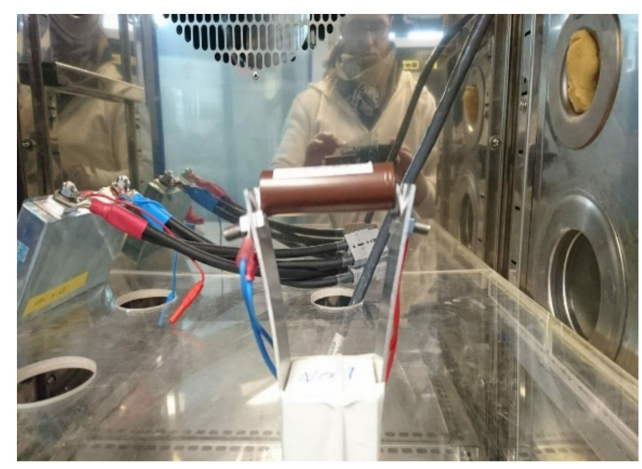

(a)

Figure 15. Cont. 


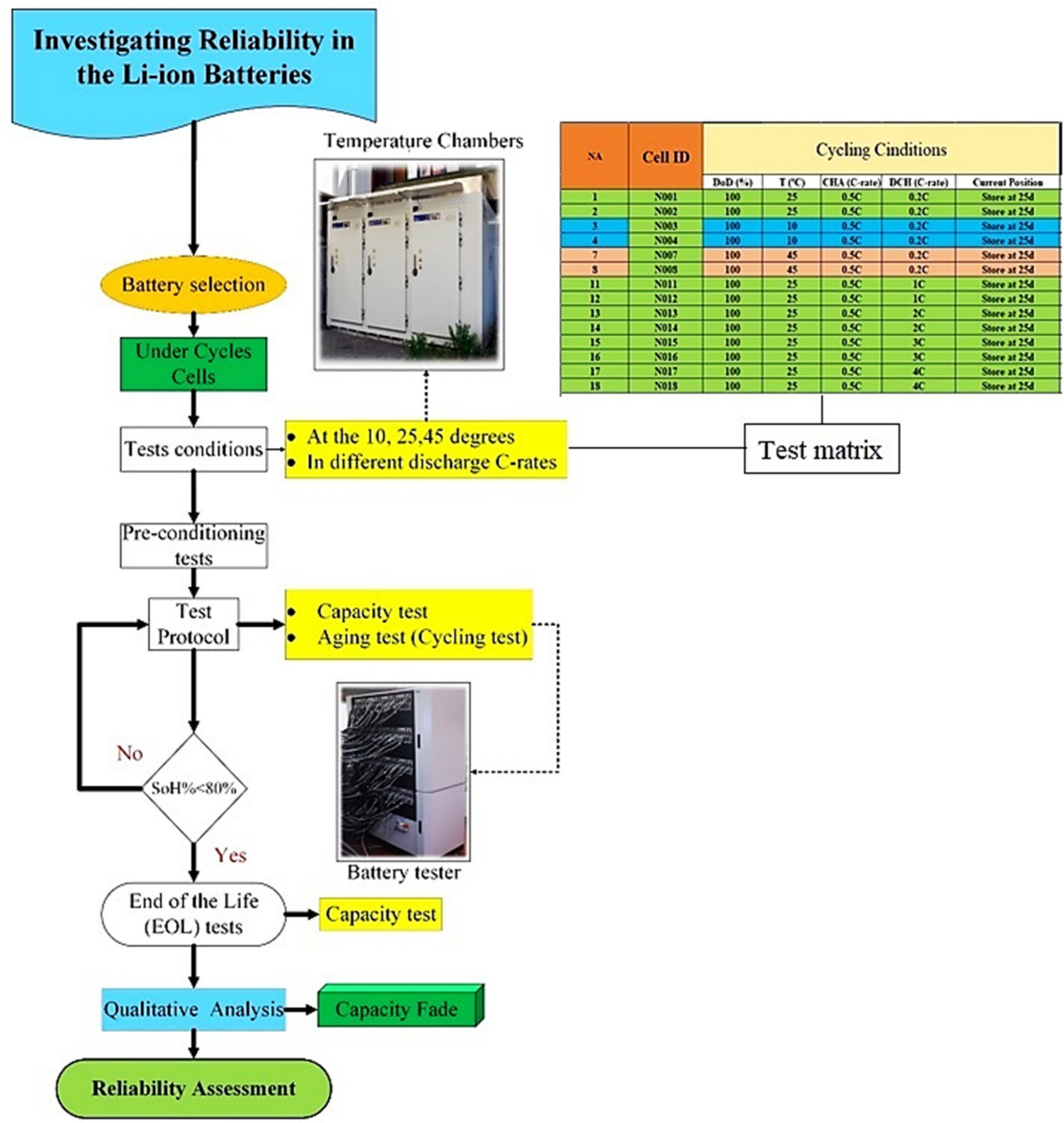

(b)

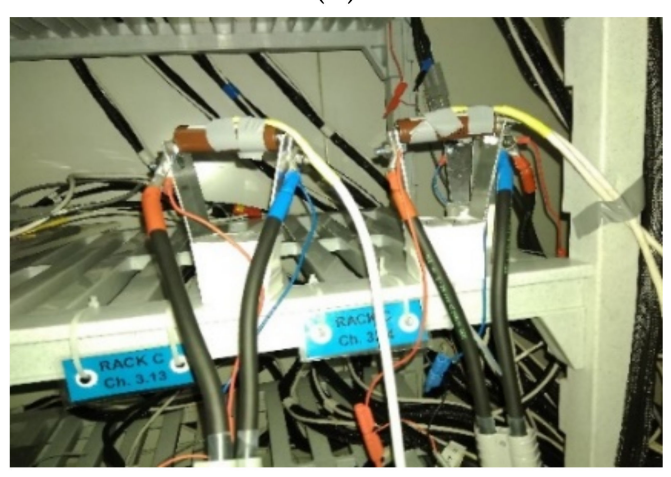

(c)

Figure 15. Reliability assessment in the Li-ion batteries: (a) Li-ion batteries under pre-conditioning test in the climate chambers, (b) test workflow, and (c) Li-ion batteries under cycling test in the climate chambers. 
In the action plan, 18 cells (two for each degradation condition) are considered. The first column shows the ID number of each cell. The second column indicated cycling/degradation conditions. The third column illustrated the per condition of the test protocol, which contains the BoL date of each cell.

Figure $16 \mathrm{a}, \mathrm{b}$ show the $\mathrm{CF}$, SoH behavior, and SoH at different temperatures and under charge-discharge standard test protocols during the battery's lifetime. According to the results, a reduction in battery capacity occurred early at $10^{\circ} \mathrm{C}, 45^{\circ} \mathrm{C}$, and $25^{\circ} \mathrm{C}$. Moreover, the test results after 300 cycles at different temperatures are shown. The reliability of the battery from $\mathrm{CF}$ and $\mathrm{SoH}$ perspectives is acceptable at $25^{\circ} \mathrm{C}(88 \%), 45^{\circ} \mathrm{C}(85 \%)$, and $10{ }^{\circ} \mathrm{C}(80 \%)$, respectively. The SoH distribution at different temperatures is displayed in Figure $16 \mathrm{~b}$ to have a comprehensive overview regarding CF of the Li-ion batteries at different temperatures and under charge-discharge standard test protocols. The SoH distribution has three main specifications; the right part of the figure shows the rate of the $\mathrm{SoH}$ of the batteries based on the percentage, the bottom part describes the number of the checkup tests (capacity tests), and the left side of the proposed investigation presents the number of the degradation conditions. In this case study, three main temperatures have been considered as degradation conditions for providing a comprehensive overview of the battery capacity behaviors at high, low, and temperatures room temperature $\left(25^{\circ} \mathrm{C}\right)$.

The capacity fade has a strong connection with ambient temperature and the best operating condition is $25^{\circ} \mathrm{C}$ among the other conditions; this is because the rate of capacity fade after 300-time cycles and the uniformity of the capacity reduction is less and better than other conditions, respectively. Low temperature $\left(10{ }^{\circ} \mathrm{C}\right.$ in this case $)$ can increase lithium plating more than other ambient temperatures; this issue is the main reason behind leading the Li-ion batteries to have high-capacity fade among other ambient temperatures. Additionally, cycling of the batteries at high temperatures results in accelerated SEI growth, and above a certain temperature threshold, we will experience decomposition of the electrolyte of the solid electrolyte interferes and of the binder material which holds the electrodes together. In such cases, Li-ion batteries have experienced the dissolution of transition metals from the cathode into the electrolyte, whereas charging and discharging at lower temperatures risks inducing lithium plating of the anode, and additional energy cycles will cause SEI growth and increase the likelihood of structural disordering.

\subsection{Capacity Fade and SoH under Different Charge-Discharge Test Protocols}

Figure $17 \mathrm{a}, \mathrm{b}$ show the $\mathrm{CF}$, SoH behavior, and $\mathrm{SoH}$ at $25^{\circ} \mathrm{C}$ and under different standard charge-discharge test protocols. According to the results, a reduction in battery capacity occurred earlier at $4 \mathrm{C}$. A comprehensive overview is displayed in Figure $17 \mathrm{~b}$ regarding $\mathrm{CF}$ of the Li-ion batteries at $25^{\circ} \mathrm{C}$ in standard charge, different discharge test protocols, and SoH distribution at different temperatures. In this investigation, five domains of $C$-rate discharge have been considered as degradation conditions for providing a comprehensive overview of the battery capacity behaviors in multi-domain discharge current conditions. 


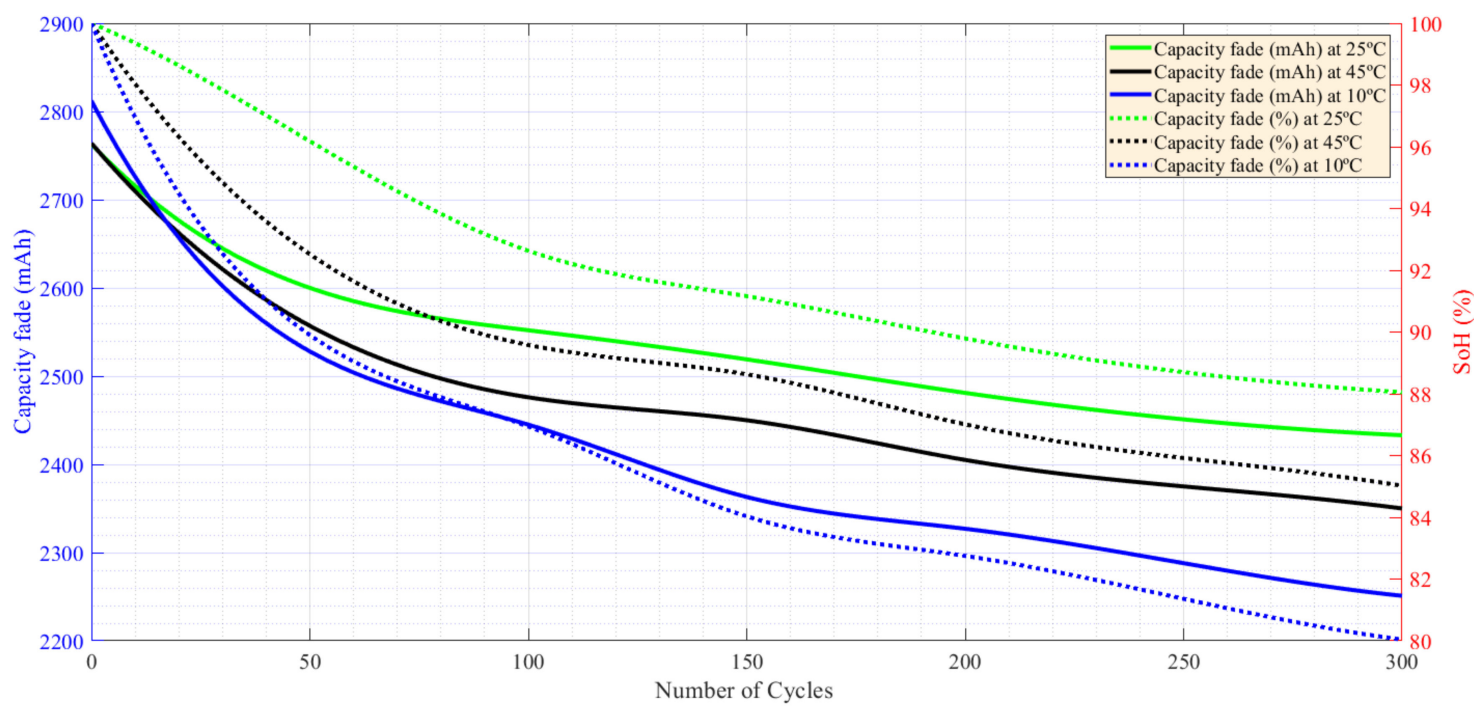

(a)

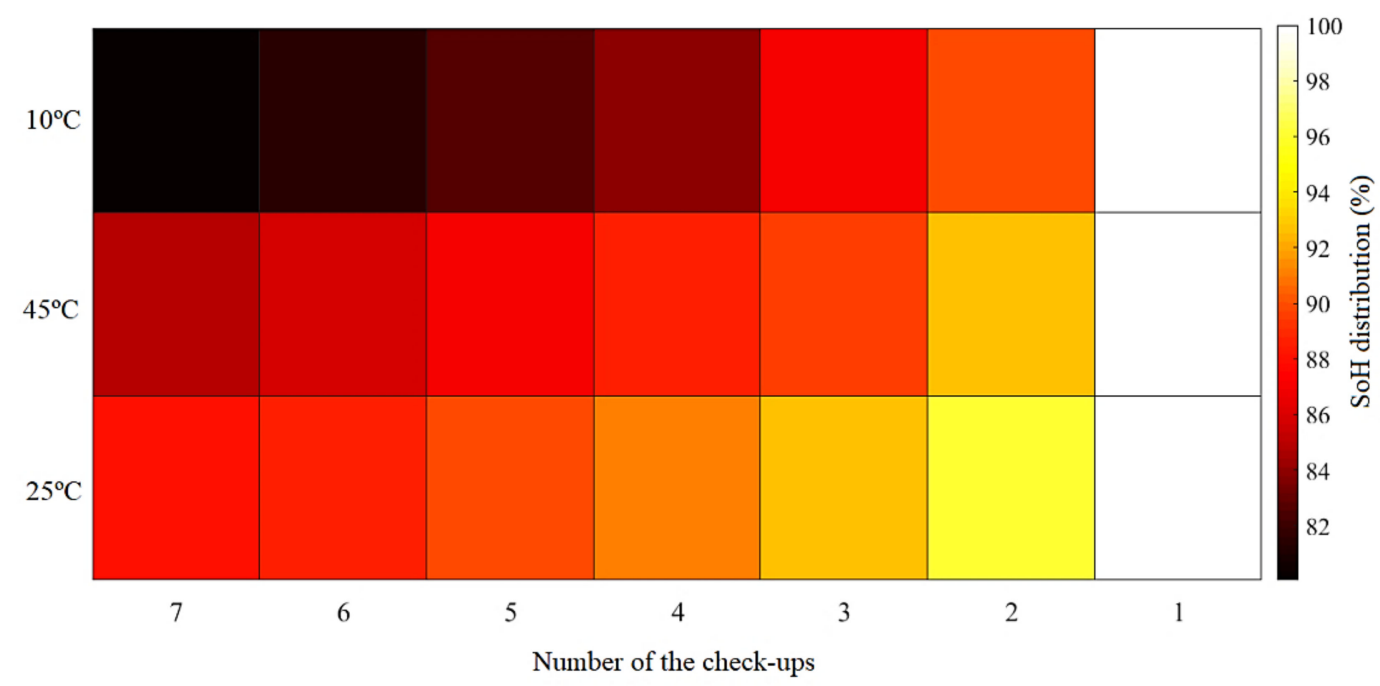

(b)

Figure 16. Reliability assessment in the Li-ion batteries: (a) $\mathrm{CF}$ and $\mathrm{SoH}$ behavior, and (b) SoH distribution different temperatures under charge-discharge standard test protocols during the battery lifetime.

The $C$-rate is the rate of charge or discharge which correlates with the rate of lithiation of the electrode material. Historically, higher $C$-rate results in accelerated capacity fade due to mechanical-induced damage of active particles. Thus, the SoH distribution result shows here, using a battery with a high discharge current reduces the capacity faster than a low discharge $C$-rate during the lifetime of the battery. High $C$-rate is a factor that impacts more on the SEI growth (mechanical stress), SEI decomposition, Grafit exfoliation, structure disordering, islanding formation, and finally loss of the electrical conductivity. The mentioned degradation modes affect the loss of cyclable Li and loss of active material, which is the key cause of capacity fade at high discharge $C$-rate in the Li-ion batteries. 


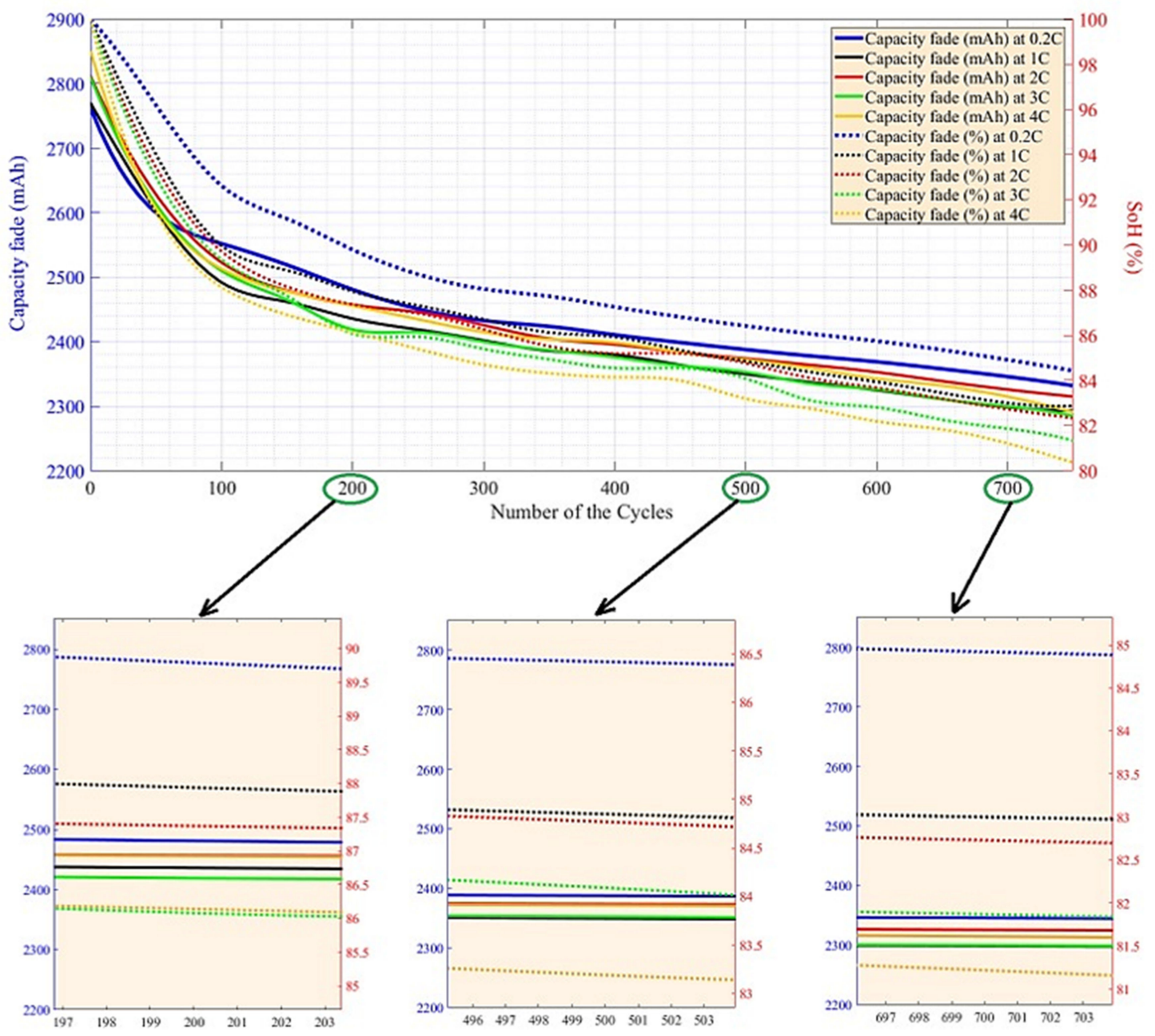

(a)

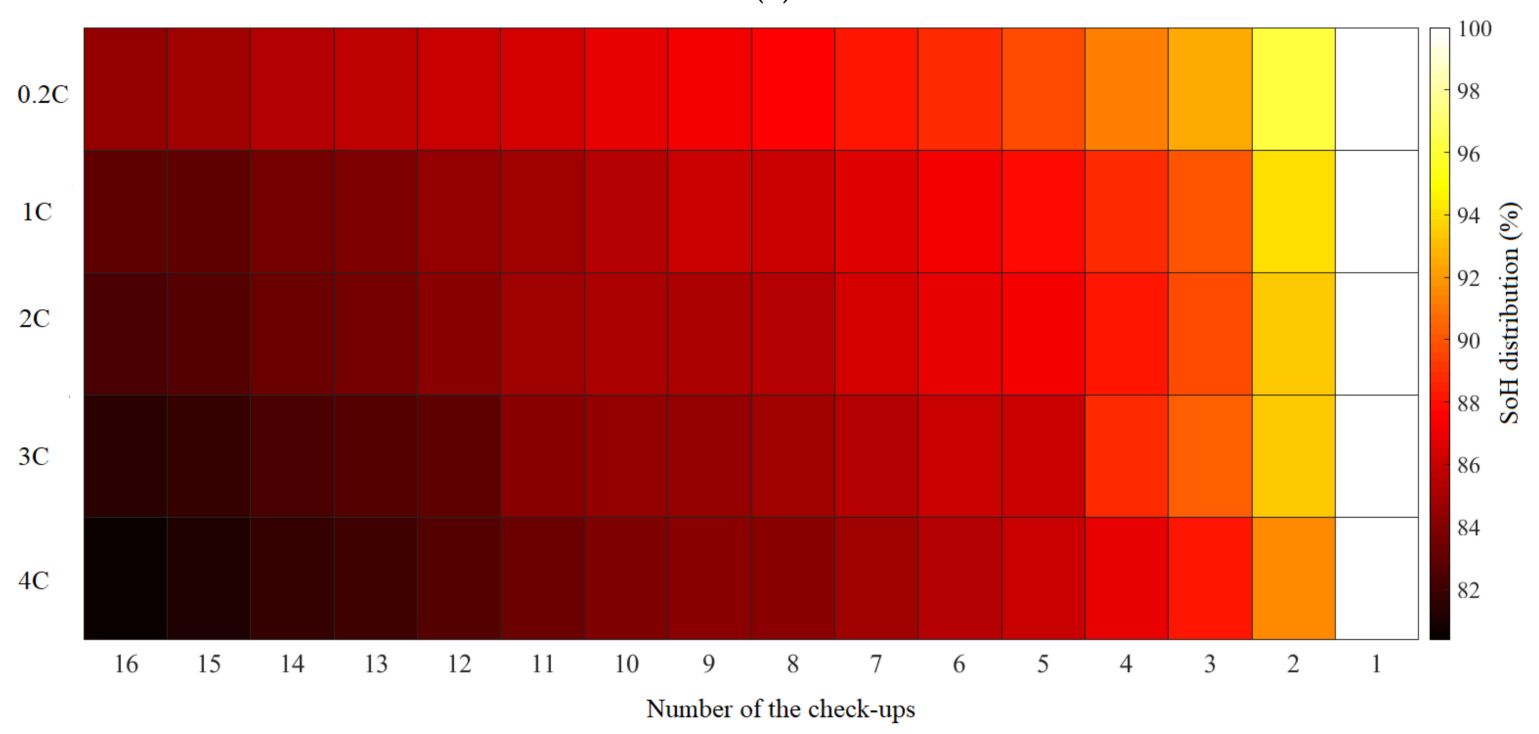

(b)

Figure 17. Reliability assessment in the Li-ion batteries: (a) $\mathrm{CF}$ and $\mathrm{SoH}$ behavior at $25^{\circ} \mathrm{C}$ and (b) SoH distribution under different discharge current test protocols during the battery lifetime. 


\section{Conclusions}

A comprehensive overview of the reliability evaluation of Li-ion batteries is presented in this work. The degradation conditions from different discharge $C$-rate and ambient temperatures during the life span of the NMC batteries have been considered in the test case to show a better understanding of the concept of reliability of the Li-ion batteries from the $\mathrm{CF}$ perspective. According to the case study results, the reliability of $\mathrm{Li}$-ion batteries (determined by standard test protocols) at $10{ }^{\circ} \mathrm{C}$ and high $\mathrm{C}$-rate is lower than in other conditions. In other words, by decreasing the environment temperature and increasing the discharge $C$-rate during the battery's lifetime, the battery's reliability decreases. The result obtained shows that the capacity fade and power fade have been increased by $10^{\circ} \mathrm{C}$ and $4{ }^{\circ} \mathrm{C}$, respectively, more than in other conditions. Moreover, the dependable conditions for performing the batteries are at $25^{\circ} \mathrm{C}$ and $\mathrm{C} / 2$ and $1 \mathrm{C}$ discharge at $25^{\circ} \mathrm{C}$ during the lifetime of the batteries.

Author Contributions: F.H.G. designed the case under study, performed the simulations, and obtained the results; M.B. and S.H.E.A.A. analyzed the obtained results; F.H.G. and E.M.A. wrote the paper, which was further reviewed by E.M.A., M.B., Z.M.A., A.F.Z. and S.H.E.A.A. All authors have read and agreed to the published version of the manuscript.

Funding: This work was funded by the Deanship of Scientific Research at Jouf University under grant No (DSR-2021-02-0309).

Institutional Review Board Statement: Not applicable.

Informed Consent Statement: Not applicable.

Data Availability Statement: The data presented in this study are available on request from the corresponding author. The data are not publicly available due to their large size.

Acknowledgments: The authors acknowledge with thanks the Deanship of Scientific Research at Jouf University, Saudi Arabia (Grant No. DSR-2021-02-0309) for their technical and financial support. Also, the authors would like to acknowledge the support of the research team from "Flanders Make".

Conflicts of Interest: The authors declare no conflict of interest.

\section{References}

1. Zobaa, A.F.; Aleem, S.H.E.A.; Abdelaziz, A.Y. Classical and Recent Aspects of Power System Optimization; Academic Press: Cambridge, MA, USA; Elsevier: Amsterdam, The Netherlands, 2018; ISBN 9780128124413.

2. Opitz, A.; Badami, P.; Shen, L.; Vignarooban, K.; Kannan, A.M. Can Li-Ion batteries be the panacea for automotive applications? Renew. Sustain. Energy Rev. 2017, 68, 685-692. [CrossRef]

3. InteGrated and PHysically Optimised Battery System for Plug-In Vehicles Technologies; European Commission: Brussels, Belgium; Luxembourg, 2021.

4. Peters, J.F.; Baumann, M.; Zimmermann, B.; Braun, J.; Weil, M. The environmental impact of Li-Ion batteries and the role of key parameters-A review. Renew. Sustain. Energy Rev. 2017, 67, 491-506. [CrossRef]

5. Jaguemont, J.; Boulon, L.; Dubé, Y. A comprehensive review of lithium-ion batteries used in hybrid and electric vehicles at cold temperatures. Appl. Energy 2016, 164, 99-114. [CrossRef]

6. Das, U.K.; Shrivastava, P.; Tey, K.S.; Bin Idris, M.Y.I.; Mekhilef, S.; Jamei, E.; Seyedmahmoudian, M.; Stojcevski, A. Lithium-ion battery aging mechanisms and diagnosis method for automotive applications: Recent advances and perspectives. Renew. Sustain. Energy Rev. 2020, 134, 110227. [CrossRef]

7. Dubarry, M.; Liaw, B.Y. Identify capacity fading mechanism in a commercial LiFePO4 cell. J. Power Sources 2009, 194, 541-549. [CrossRef]

8. Chung, S.H.; Tancogne-Dejean, T.; Zhu, J.; Luo, H.; Wierzbicki, T. Failure in lithium-ion batteries under transverse indentation loading. J. Power Sources 2018, 389, 148-159. [CrossRef]

9. Gandoman, F.H.; Ahmadi, A.; Van den Bossche, P.; Van Mierlo, J.; Omar, N.; Nezhad, A.E.; Mavalizadeh, H.; Mayet, C. Status and future perspectives of reliability assessment for electric vehicles. Reliab. Eng. Syst. Saf. 2019, 183, 1-16. [CrossRef]

10. Mertens, A.; Vinke, I.C.; Tempel, H.; Kungl, H.; De Haart, L.G.J.; Eichel, R.-A.; Granwehr, J. Quantitative analysis of time-domain supported electrochemical impedance spectroscopy data of Li-ion batteries: Reliable activation energy determination at low frequencies. J. Electrochem. Soc. 2016, 163, H521-H527. [CrossRef]

11. Collong, S.; Kouta, R. Fault tree analysis of proton exchange membrane fuel cell system safety. Int. J. Hydrogen Energy 2015, 40, 8248-8260. [CrossRef] 
12. Levy, S.C. Safety and reliability considerations for lithium batteries. J. Power Sources 1997, 68, 75-77. [CrossRef]

13. Hendricks, C.; Williard, N.; Mathew, S.; Pecht, M. A failure modes, mechanisms, and effects analysis (FMMEA) of lithium-ion batteries. J. Power Sources 2015, 297, 113-120. [CrossRef]

14. Ali Kadhem, A.; Abdul Wahab, N.I.; Aris, I.; Jasni, J.; Abdalla, A.N. Computational techniques for assessing the reliability and sustainability of electrical power systems: A review. Renew. Sustain. Energy Rev. 2017, 80, 1175-1186. [CrossRef]

15. Escalera, A.; Hayes, B.; Prodanović, M. A survey of reliability assessment techniques for modern distribution networks. Renew. Sustain. Energy Rev. 2018, 91, 344-357. [CrossRef]

16. Gandoman, F.H.; Jaguemont, J.; Goutam, S.; Gopalakrishnan, R.; Firouz, Y.; Kalogiannis, T.; Omar, N.; Van Mierlo, J. Concept of reliability and safety assessment of lithium-ion batteries in electric vehicles: Basics, progress, and challenges. Appl. Energy 2019, 251, 113343. [CrossRef]

17. Leng, F.; Tan, C.M.; Yazami, R.; Maher, K.; Wang, R. Quality decision for overcharged li-ion battery from reliability and safety perspective. In Theory and Practice of Quality and Reliability Engineering in Asia Industry; Springer: Singapore, 2017; ISBN 9789811032905.

18. Liu, Z.; Tan, C.; Leng, F. A reliability-based design concept for lithium-ion battery pack in electric vehicles. Reliab. Eng. Syst. Saf. 2015, 134, 169-177. [CrossRef]

19. Xiong, R.; Pan, Y.; Shen, W.; Li, H.; Sun, F. Lithium-ion battery aging mechanisms and diagnosis method for automotive applications: Recent advances and perspectives. Renew. Sustain. Energy Rev. 2020, 131, 110048. [CrossRef]

20. Gao, Y.; Zhang, X.; Yang, J.; Guo, B.; Zhou, X. A novel model for lithium-ion battery aging quantitative analysis based on pseudo two-dimension expressions. Int. J. Electrochem. Sci. 2019, 14, 3180-3203. [CrossRef]

21. Bubbico, R.; Greco, V.; Menale, C. Hazardous scenarios identification for Li-ion secondary batteries. Saf. Sci. 2018, 108, 72-88. [CrossRef]

22. Spotnitz, R. Simulation of capacity fade in lithium-ion batteries. J. Power Sources 2003, 113, 72-80. [CrossRef]

23. Zhang, J.; Lee, J. A review on prognostics and health monitoring of Li-ion battery. J. Power Sources 2011, 196, 6007-6014. [CrossRef]

24. Abraham, D.; Liu, J.; Chen, C.; Hyung, Y.; Stoll, M.; Elsen, N.; MacLaren, S.; Twesten, R.; Haasch, R.; Sammann, E.; et al. Diagnosis of power fade mechanisms in high-power lithium-ion cells. J. Power Sources 2003, 119-121, 511-516. [CrossRef]

25. Miao, Y.; Hynan, P.; von Jouanne, A.; Yokochi, A. Current Li-Ion Battery Technologies in Electric Vehicles and Opportunities for Advancements. Energies 2019, 12, 1074. [CrossRef]

26. Piernas Muñoz, M.J.; Castillo Martínez, E. Introduction to batteries. In Prussian Blue Based Batteries; Springer: New York, NY, USA, 2018; pp. 1-8. [CrossRef]

27. State of Charge (SOC) Determination. Available online: https://www.mpoweruk.com/soc.htm (accessed on 21 October 2021).

28. What Is C-Rate? Available online: https://batteryuniversity.com/learn/article/what_is_the_c_rate (accessed on 21 October 2021).

29. Wang, D.; Bao, Y.; Shi, J. Online lithium-ion battery internal resistance measurement application in state-of-charge estimation using the extended kalman filter. Energies 2017, 10, 1284. [CrossRef]

30. Fang, Q.; Wei, X.; Dai, H. A remaining discharge energy prediction method for lithium-ion battery pack considering SOC and parameter inconsistency. Energies 2019, 12, 987. [CrossRef]

31. Wachsman, E.D.; Lee, K.T. Lowering the temperature of solid oxide fuel cells. Science 2011, 334, 935-939. [CrossRef] [PubMed]

32. Mostafa, M.H.; Aleem, S.H.E.A.; Ali, S.G.; Abdelaziz, A.Y.; Ribeiro, P.F.; Ali, Z.M. Robust energy management and economic analysis of microgrids considering different battery characteristics. IEEE Access 2020, 8, 54751-54775. [CrossRef]

33. Mostafa, M.H.; Abdel Aleem, S.H.E.; Ali, S.G.; Ali, Z.M.; Abdelaziz, A.Y. Techno-economic assessment of energy storage systems using annualized life cycle cost of storage (LCCOS) and levelized cost of energy (LCOE) metrics. J. Energy Storage 2020, $29,101345$. [CrossRef]

34. Wang, Q.; Jiang, B.; Li, B.; Yan, Y. A critical review of thermal management models and solutions of lithium-ion batteries for the development of pure electric vehicles. Renew. Sustain. Energy Rev. 2016, 64, 106-128. [CrossRef]

35. Woody, M.; Arbabzadeh, M.; Lewis, G.M.; Keoleian, G.A.; Stefanopoulou, A. Strategies to limit degradation and maximize Li-ion battery service lifetime-Critical review and guidance for stakeholders. J. Energy Storage 2020, 28, 101231. [CrossRef]

36. Sarkar, J.; Bhattacharyya, S. Application of graphene and graphene-based materials in clean energy-related devices Minghui. Arch. Thermodyn. 2012, 33, 23-40. [CrossRef]

37. Wu, C.; Sun, J.; Zhu, C.; Ge, Y.; Zhao, Y. Research on Overcharge and Overdischarge Effect on Lithium-Ion Batteries. In 2015 IEEE Vehicle Power and Propulsion Conference (VPPC), Proceedings of the IEEE Conference on Vehicle Power and Propulsion (VPPC), Montreal, QC, Canada, 19-22 October 2015; IEEE: Piscataway, NJ, USA, 2015; pp. 1-6. [CrossRef]

38. Beletskii, E.V.; Alekseeva, E.V.; Spiridonova, D.V.; Yankin, A.N.; Levin, O.V. Overcharge cycling effect on the surface layers and crystalline structure of LiFePO4 cathodes of Li-ion batteries. Energies 2019, 12, 4652. [CrossRef]

39. Wen, J.; Yu, Y.; Chen, C. A Review on Lithium-Ion Batteries Safety Issues: Existing Problems and Possible Solutions. Mater. Express 2012, 2, 197-212. [CrossRef]

40. Li, J.; Wang, D.; Pecht, M. An electrochemical model for high C-rate conditions in lithium-ion batteries. J. Power Sources 2019, 436, 226885. [CrossRef]

41. Wu, C.; Zhu, C.; Ge, Y.; Zhao, Y. A Review on Fault Mechanism and Diagnosis Approach for Li-Ion Batteries. J. Nanomater. 2015, 2015, 631263. [CrossRef] 
42. Dubarry, M.; Truchot, C.; Liaw, B.Y. Synthesize battery degradation modes via a diagnostic and prognostic model. J. Power Sources 2012, 219, 204-216. [CrossRef]

43. Marongiu, A.; Nlandi, N.; Rong, Y.; Sauer, D.U. On-board capacity estimation of lithium iron phosphate batteries by means of half-cell curves. J. Power Sources 2016, 324, 158-169. [CrossRef]

44. Schlasza, C.; Ostertag, P.; Chrenko, D.; Kriesten, R.; Bouquain, D. Review on the aging mechanisms in Li-ion batteries for electric vehicles based on the FMEA method. In 2014 IEEE Transportation Electrification Conference and Expo (ITEC), Proceedings of the 2014 IEEE Transportation Electrification Conference and Expo (ITEC), Dearborn, MI, USA, 15-18 June 2014; IEEE: Piscataway, NJ, USA, 2014; pp. 1-6. [CrossRef]

45. Swierczynski, M.; Stroe, D.I.; Stan, A.I.; Teodorescu, R.; Laerke, R.; Kjær, P.C. Field tests experience from 1.6MW/400kWh Li-ion battery energy storage system providing primary frequency regulation service. In IEEE PES ISGT Europe 2013, Proceedings of the IEEE PES Innovative Smart Grid Technologies Conference Europe (ISGT Europe), Lyngby, Denmark, 6-9 October 2013; IEEE: Piscataway, NJ, USA, 2013; pp. 1-5. [CrossRef]

46. Yang, Q.; Xu, J.; Cao, B.; Li, X. A simplified fractional order impedance model and parameter identification method for lithium-ion batteries. PLoS ONE 2017, 12, e0172424. [CrossRef]

47. Farmann, A.; Waag, W.; Marongiu, A.; Sauer, D.U. Critical review of on-board capacity estimation techniques for lithium-ion batteries in electric and hybrid electric vehicles. J. Power Sources 2015, 281, 114-130. [CrossRef]

48. Das, U.K.; Shrivastava, P.; Tey, K.S.; Bin Idris, M.Y.I.; Mekhilef, S.; Jamei, E.; Seyedmahmoudian, M.; Stojcevski, A. Advancement of lithium-ion battery cells voltage equalization techniques: A review. Renew. Sustain. Energy Rev. 2020, 134, 110227. [CrossRef] 